Article

\title{
Evaluation of Critical Dynamic Stress and Accumulative Plastic Strain of an Unbound Granular Material Based on Cyclic Triaxial Tests
}

\author{
Qishu Zhang ${ }^{1}$, Wuming Leng ${ }^{1,2}$, Bin Zhai ${ }^{1}$, Fang $X u^{1,2, *}$, Junli Dong ${ }^{1}$ and Qi Yang ${ }^{1,2}$ \\ 1 School of Civil Engineering, Central South University, Changsha 410075, China; 174801020@csu.edu.cn (Q.Z.); \\ wmleng@csu.edu.cn (W.L.); email1995zb@csu.edu.cn (B.Z.); dongjunli@csu.edu.cn (J.D.); \\ qiyang123@csu.edu.cn (Q.Y.) \\ 2 National Engineering Laboratory for High Speed Railway Construction, Central South University, \\ Changsha 410075, China \\ * Correspondence: fangxu@csu.edu.cn
}

Citation: Zhang, Q.; Leng, W.; Zhai, B.; Xu, F.; Dong, J.; Yang, Q.

Evaluation of Critical Dynamic Stress and Accumulative Plastic Strain of an Unbound Granular Material Based on Cyclic Triaxial Tests. Materials 2021, 14, 5722. https://doi.org/10.3390/ ma14195722

Academic Editor: Gabriele Milani

Received: 26 August 2021

Accepted: 28 September 2021

Published: 30 September 2021

Publisher's Note: MDPI stays neutral with regard to jurisdictional claims in published maps and institutional affiliations.

Copyright: (c) 2021 by the authors. Licensee MDPI, Basel, Switzerland. This article is an open access article distributed under the terms and conditions of the Creative Commons Attribution (CC BY) license (https:// creativecommons.org/licenses/by/ $4.0 /)$.

\begin{abstract}
Critical dynamic stress $\left(\sigma_{\text {cri }}\right)$ and accumulative plastic strain $\left(\varepsilon_{\mathrm{p}}\right)$ are primary indicators regarding the dynamic stability of unbound granular materials (UGMs). This study aims to seek an effective method to evaluate the dynamic stability of UGMs used in railway subgrades. First, the dynamic characteristics of an UGM used in railway subgrade bed construction were investigated by performing a series of large-scale cyclic triaxial tests, with the results showing that $\varepsilon_{\mathrm{p}}$ versus cycle number $(N)$ curves can be categorized into stable, failure, and critical patterns. Grey relational analyses were then established, where the analyzed results demonstrated that the $\varepsilon_{\mathrm{p}}-N$ curve pattern and final accumulative plastic strain $\left(\varepsilon_{\mathrm{s}}\right)$ of the stable curves are strongly correlated with the moisture content $(w)$, confining pressure $\left(\sigma_{3}\right)$, and dynamic deviator stress $\left(\sigma_{\mathrm{d}}\right)$. The analyzed grey relational grades distributed in a narrow range of 0.72 to 0.81 , indicating that $w, \sigma_{3}$, and $\sigma_{\mathrm{d}}$ have similar degrees of importance on determining the $\varepsilon_{\mathrm{p}}-N$ curve patterns and the values of $\varepsilon_{\mathrm{s}}$ of the UGM. Finally, a data processing method using a back-propagation (BP) neural network is introduced to analyze the test data, and an empirical approach is developed to evaluate the $\sigma_{\text {cri }}$ (considering the effects of $\sigma_{3}$ and $w$ ) and $\varepsilon_{\mathrm{S}}$ (considering the effects of $\sigma_{3}, w$, and $\sigma_{\mathrm{d}}$ ) of the UGM. The analyzed results illustrated that the developed method can effectively reflect the linear/non-linear relationships of $\sigma_{\text {cri }}$ and $\varepsilon_{\mathrm{s}}$ with respect to $\sigma_{3}$ and/or $\sigma_{\mathrm{d}}$. The $\sigma_{\text {cri }}$ approximately increases linearly with increasing $\sigma_{3}$, and a simple empirical formula is proposed for the $\sigma_{\text {cri }}$. In addition, $\varepsilon_{\mathrm{S}}$ and its variation rate increase non-linearly with increasing $\sigma_{\mathrm{d}}$ but decrease non-linearly as $\sigma_{3}$ increases.
\end{abstract}

Keywords: unbound granular materials; critical dynamic stress; accumulative plastic strain; cyclic triaxial test; BP neural network

\section{Introduction}

The serviceability of railway tracks is strongly associated with the dynamic stability of unbound granular layers atop weaker layers of the subgrades, of which the critical dynamic stress $\left(\sigma_{\text {cri }}\right)$ and accumulative plastic/permanent stain $\left(\varepsilon_{\mathrm{p}}\right)$ are primary indicators regarding the dynamic stability of unbound granular materials (UGMs) [1-6]. Subgrades of railways accumulate permanent settlement under dynamic traffic loading, and excessive accumulative surface settlement typically causes problems, such as vehicle turbulence in transition sections [7,8], uneven settlement [9-11], and lateral expansion of embankment shoulders [12-14]. One of the most effective ways to control the accumulative deformation of subgrades is maintaining the traffic-induced dynamic stress to be less than a critical value (i.e., the $\sigma_{\text {cri }}$ ), under which the development rate of $\varepsilon_{\mathrm{p}}$ gradually decreases and can ultimately cease with an increase in the dynamic loading cycles $[5,15,16]$. Furthermore, the rapid development of high-speed transport and heavy-haul freight demands the subgrades beneath track structures must satisfy strict requirements on accumulative permanent 
settlements [17-19]. Therefore, evaluations of the critical dynamic stress and accumulative plastic strain of the UGM layers are important in the design of a railway.

The cyclic triaxial test is an efficient way to study the critical dynamic stress of subgrade materials [20-23]. Qualitative analyses of critical dynamic stress of different types of materials showed that $\sigma_{\mathrm{cri}}$ is linked to the saturation degree, stress history, and dynamic loading path of the materials $[15,24]$. Cheung et al. [25] designated the stress level under which $1 \%$ accumulative permanent strain was generated within 1000 loading cycles as the $\sigma_{\text {cri }}$. Frost et al. [26] presented that the $\sigma_{\text {cri }}$ of fine-grained subgrades is approximately half of the deviator stress corresponding to static destruction. Wang et al. [27] reported that the initial stress state could considerably affect the $\sigma_{\text {cri }}$ of a silty clay. Recently, a few empirical models were developed to predict the $\sigma_{\text {cri }}$; Zhang et al. [28] developed a regression model for predicting the $\sigma_{\text {cri }}$ based on the fuzzy linear regression theory and structural element method. Xu et al. [6] presented an empirical method to predict the $\sigma_{\text {cri }}$ by introducing the concept of critical stress ratio; Zhai et al. [16] predicted the $\sigma_{\text {cri }}$ of UGMs as a function of confining pressure based on results of cyclic triaxial tests of specimens with optimal moisture content. Most existing studies on $\sigma_{\text {cri }}$ were qualitative investigations. Several evaluation models of $\sigma_{\text {cri }}$ have also been proposed on the basis of cyclic triaxial tests; however, the factors considered in the models regarding the $\sigma_{\text {cri }}$ of UGMs are incomplete, and systematic studies of $\sigma_{\text {cri }}$ considering the effects of both moisture content and confining pressure are desirable.

The cyclic triaxial test is also commonly used to study the accumulative plastic deformation of UGMs. Generally, the $\varepsilon_{\mathrm{p}}$ versus cycle number $(N)$ curves can be identified from a cyclic triaxial test. Instances of commonly used relationships are the power-function [29], semi-logarithmic [30], and hyperbolic models [31], which simply reflect the variation relationship between the $\varepsilon_{\mathrm{p}}$ and dynamic loading cycles; therefore, modifications have been proposed with considerations of the effects of stress path, static strength, confining pressure, etc. Li and Selig [32] extended the power function model while including the physical state and static strength of the tested soil; Chai and Miura [33] then extended the method of Li and Selig [32] by incorporating the initial static deviator stress $\left(\sigma_{\mathrm{si}}\right) ; \mathrm{Wu}$ et al. [34] improved the original power-function model while considering the effects of cyclic stress ratio. Moghaddas-Nejad and Small [35] improved the semi-logarithmic model by incorporating confining pressure and dynamic deviator stress; Stewart [36] extended the model by including the stress path; $\mathrm{Xu}$ et al. [37] developed a probabilistic method to predict $\varepsilon_{\mathrm{p}}$ of UGMs based on the semi-logarithmic model. In addition, a few models in different formulations were also proposed to predict the $\varepsilon_{\mathrm{p}}$. Lekarp et al. [38] formulated $\varepsilon_{\mathrm{p}}$ using the length of the stress path and shear stress ratio. El-Badawy and Witczak [39] predicted $\varepsilon_{\mathrm{p}}$ as a function of stress state, plasticity index, resilient response, saturation degree, $N$, fine contents, and material strength. Xiao et al. [40] proposed a unified prediction model of $\varepsilon_{\mathrm{p}}$ using the imaging-based morphological indexes of aggregate and concept of shear stress ratio.

The existing methods generally predict the $\varepsilon_{\mathrm{p}}$ well within small loading cycles. However, they may overestimate the $\varepsilon_{\mathrm{p}}$ of UGMs under large loading cycles because most of them demonstrate a monotonic increasing relationship between $\varepsilon_{\mathrm{p}}$ and $N$, which is contrary to the fact that the rate of $\varepsilon_{\mathrm{p}}$ of stable specimens gradually declines and finally ceases when the material enters a shakedown state $[4,16,41]$. Moreover, comparing with predicting the development trend of $\varepsilon_{p}$, it is more practical to evaluate the final accumulative deformation of the UGM layers in the design of a railway subgrade.

In this study, the dynamic stability of an UGM under long-term dynamic loading was investigated by a series of large-scale cyclic triaxial tests. The main influencing factors and their influencing extent regarding the dynamic stability of the UGM were identified by grey relational analyses of the test results. Then, a data processing method in combination with a back-propagation (BP) neural network is introduced, from which an approach is developed to evaluate the $\sigma_{\text {cri }}$ (considering the effects of $\sigma_{3}$ and $w$ ) and final $\varepsilon_{\mathrm{p}}\left(\varepsilon_{\mathrm{s}}\right.$, considering the effects of $\sigma_{3}, w$, and $\sigma_{\mathrm{d}}$ ) of the UGM, where the analyzed results demonstrated that the 
developed method can effectively describe the linear/non-linear behavior of $\sigma_{\text {cri }}$ and $\varepsilon_{\mathrm{s}}$ regarding the confining pressure $\left(\sigma_{3}\right)$ and/or dynamic deviator stress $\left(\sigma_{\mathrm{d}}\right)$.

\section{Test Materials and Methods}

The tests were performed using a UGM consisted by fine particles, sand, and gravel. The particle size $(d)$ gradation curve of the UGM is presented in Figure 1. The specific gradation properties of the UGM are $d_{60}=6 \mathrm{~mm}, d_{30}=0.75 \mathrm{~mm}, d_{10}=0.066 \mathrm{~mm}, d_{\max }=50 \mathrm{~mm}$, $C_{\mathrm{c}}=1.42$, and $C_{\mathrm{u}}=80$, where $d_{60}, d_{30}, d_{10}, d_{\max }, C_{\mathrm{c}}$, and $C_{\mathrm{u}}$ are the particle diameters corresponding to $60 \%, 30 \%$, and $10 \%$ finer, maximum diameter, coefficient of curvature, and coefficient of uniformity, respectively. The tested UGM is categorized as a Group A subgrade bed filling in line with a railway standard of China [42] and belongs to the silty gravel group by following the Unified Soil Classification System of ASTM D2487-17e1 [43].

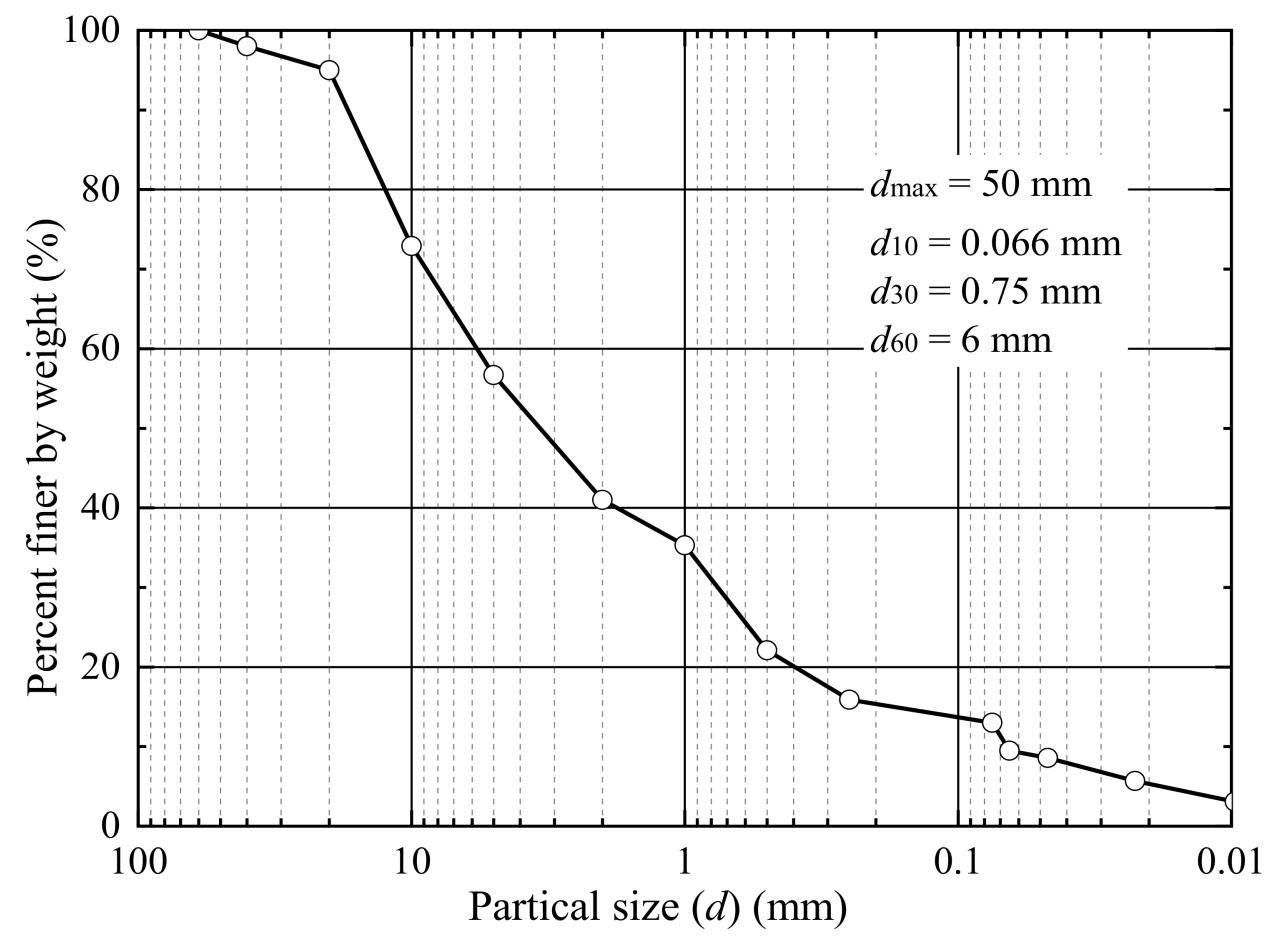

Figure 1. Particle size gradation curve of the UGM [16,37].

The compaction curve of the UGM was tested by following the ASTM D1577-12 compaction standard using the modified proctor [44], as presented in Figure 2. In the compaction test, the UGM with different moisture contents was compacted using modified proctor with straightforward compaction energy, and the moisture contents after compaction were measured. Figure 2 also presents the zero air void curve of the UGM and basic physical parameters of each group of compacted material, including the specific gravity $\left(G_{\mathrm{s}}\right)$, final void ratio $(e)$, and final saturation degree $\left(S_{\mathrm{r}}\right)$. Meanwhile, it can be determined from the compaction curve that the optimal moisture content $\left(w_{\mathrm{o}}\right)$ and maximum dry density $\left(\rho_{\mathrm{dmax}}\right)$ of the UGM are $6.2 \%$ and $2.21 \mathrm{~g} / \mathrm{cm}^{3}$, respectively.

Large-scale cyclic triaxial test equipment was used to perform the tests, which mainly consisted of a confining cell and a loading frame. The loading frame can generate dynamic or monotonic loadings on the tested specimens, of which the maximum loading value is $50 \mathrm{kN}$; the test device can therefore conduct both cyclic and static triaxial tests. Figure 3 presents a photograph of the used test device, where the displacement gauge installed on the actuator has a precision of $0.01 \mathrm{~mm}$, and variations in the specimen axil displacement during the test were recorded using a computer linked to a data logger. 


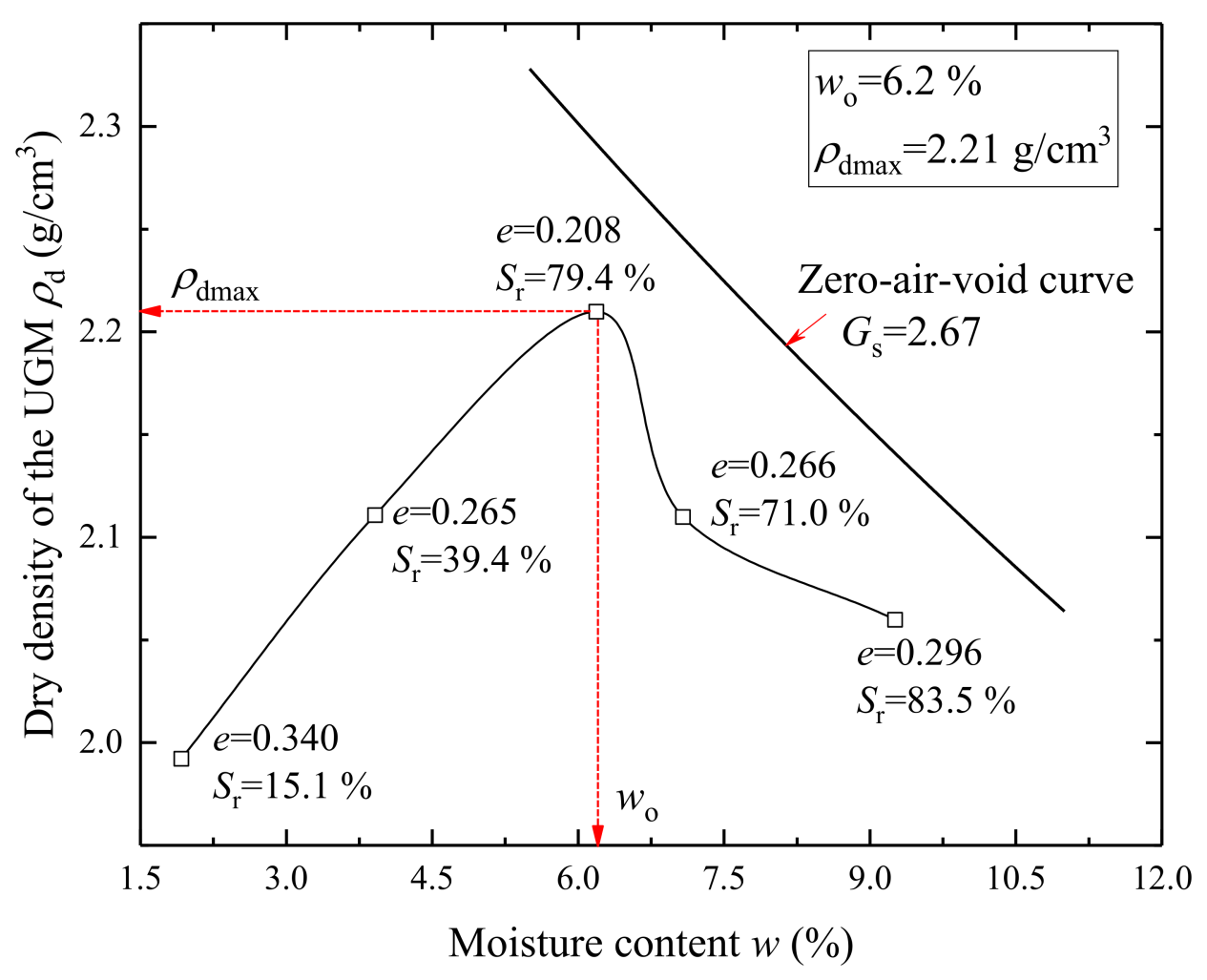

Figure 2. Compaction curve of the UGM.

The prominent advantage of the test equipment is that it can facilitate tests on subgrade soils with large particle sizes. According to the ASTM D7181-20 standard [45], the diameter of specimens is required to be no less than six times the $d_{\max }$ of the soil for reducing the size effects of specimens on the test data. Currently, a large proportion of triaxial devices are manufactured for conducting tests with soil specimen diameters less than $150 \mathrm{~mm}$ (e.g., $39.1,50,100$ and $150 \mathrm{~mm}$ ) [46-49]. However, the $d_{\max }$ of UGMs used as railway subgrade fillings is generally within the range of $50-60 \mathrm{~mm}$ as specified by a railway standard of China [42]. Therefore, regular cyclic triaxial devices cannot satisfy the requirement on the ratio of specimen diameter to $d_{\max }$. The used test equipment can facilitate tests of specimens with a diameter of $300 \mathrm{~mm}$. The ratio of specimen diameter to $d_{\max }$ is therefore six in the present study, which satisfies the specification of ASTM D7181-20 standard [45].

Consistent compaction efforts were adopted in preparing the cyclic triaxial test specimens to ensure the reliability of test results. Similar to the compaction test, the UGM was first scattered, and then mixed by adding distilled water to reach the optimal moisture content and kept in a hermetic plastic bag to humidify for more than $48 \mathrm{~h}$ to homogenize the moisture content. The height and diameter of the specimens were $300 \mathrm{~mm}$ and $600 \mathrm{~mm}$, respectively. To ensure the consistence of the prepared specimens, it was required to control the moist mass added, the thickness of each compacted layer, and the compaction efforts. In this study, the UGM with optimal moisture content was compacted into a steel specimen preparation mold by six layers, with each layer having the same moist mass of $16.065 \mathrm{~kg}$. Then, each incompact layer was compacted to a target thickness of $100 \mathrm{~mm}$ using a $17 \mathrm{~kg}$ steel impact hammer with a drop distance of approximately $500 \mathrm{~mm}$, to attain a target compaction degree of 0.97 . It should be noted that keeping consistent layer moist mass added, consistent compaction layer thickness, and consistent impact hammer mass and drop distance (i.e., compaction efforts) is helpful to ensure the consistency of the triaxial UGM specimens. 


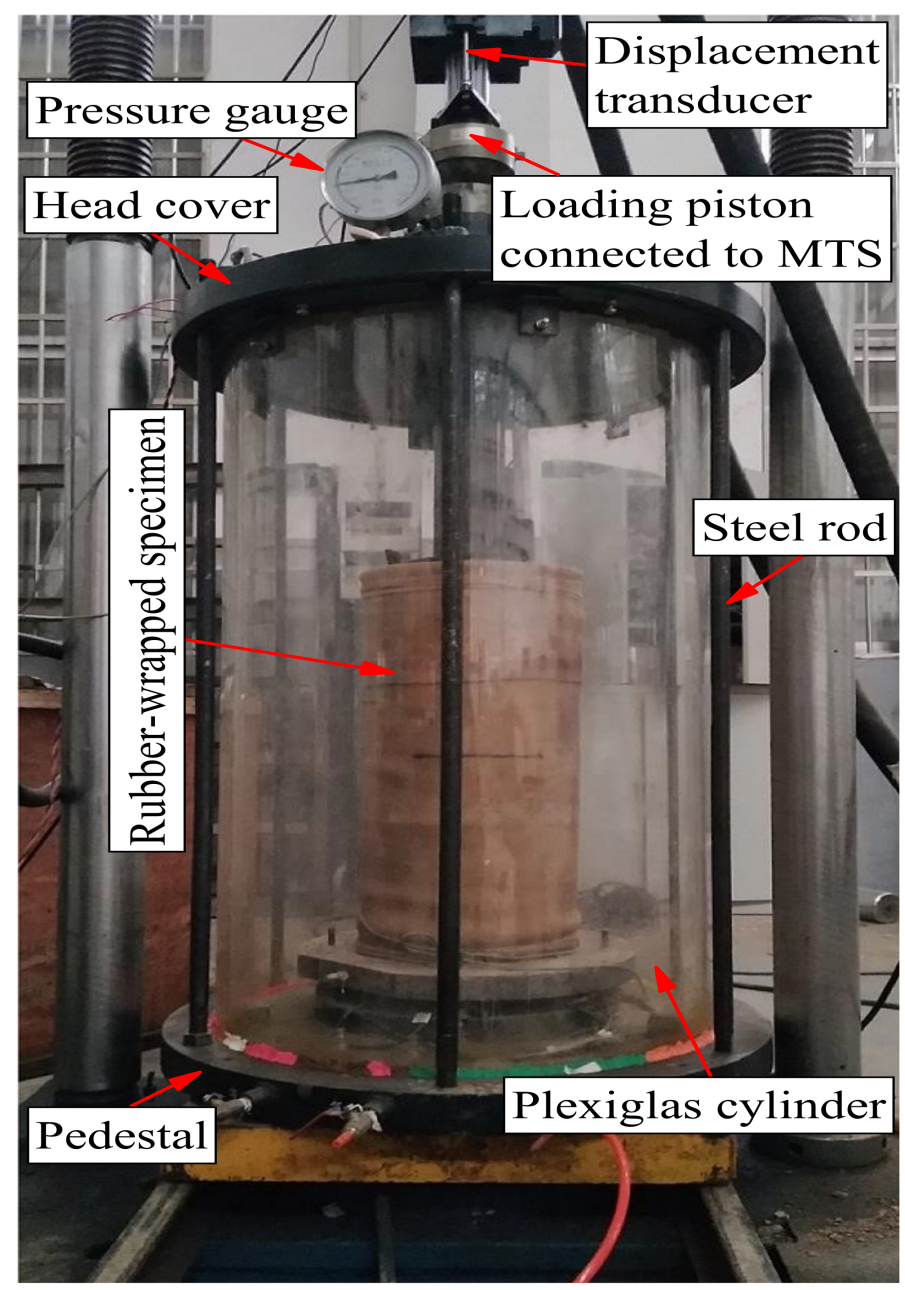

Figure 3. Photograph of the test device [16,37].

Both optimal moisture content and saturation specimens were tested in the cyclic triaxial tests. The specimens with optimal moisture content were achieved by controlling the amount of distilled water added in the UGM, which corresponded to a saturation degree of $79.4 \%$, as presented in Figure 2. The full saturation of UGM specimens was achieved by the following steps: (1) the specimens were firstly pre-saturated using vacuum suction for $2 \mathrm{~h}$; (2) further saturation of the UGM specimens was achieved by injecting compressed carbon dioxide $\left(\mathrm{CO}_{2}\right)$ and then distilled water from the bottom to the top of the specimens with a small confining pressure to reach a stationary flow state; (3) finally, back pressure was applied to reach a minimum pore pressure coefficient value of 0.95 . Similar methods to ensure full saturation of specimens were also reported and recommended by Mehdizadeh [50].

In this study, 28 large-scale cyclic triaxial tests were performed, and the specific test schemes are listed in Table 1. Based on the field data reported by the China Academy of Railway Science, the maximum dynamic stress of railway subgrades is discrete in a range of 35-185 kPa when the train axle load is within 19.6-22.5 t [51]. Moreover, to consider a future developing trend that the heavy-haul train axle load will increase up to $35 \mathrm{t}$ and investigate the $\sigma_{\text {cri }}$ of the UGM, this study expanded the value range of the deviator stress $\sigma_{\mathrm{d}}$. Specifically, the range of $\sigma_{\mathrm{d}}$ for the tested saturation specimens and optimal moisture content specimens are 50-250 kPa and 100-400 kPa, respectively. Moreover, the operation speed of heavy-haul freight trains is much less than the normal and high-speed passenger trains; for instance, the operation speed of heavy-haul freight trains in China is mainly

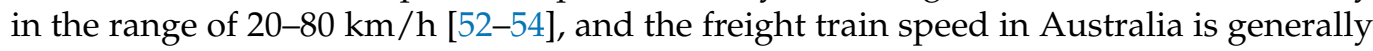


within $40-80 \mathrm{~km} / \mathrm{h}[55,56]$. The wagon length of freight trains in China is 12-14 $\mathrm{m}$ [57]. In the cyclic triaxial tests, a $1 \mathrm{~Hz}$ sine-wave cyclic deviator stress was applied by closing the drainage valve, which corresponded to a typical operation speed of $50 \mathrm{~km} / \mathrm{h}$ for the heavy-haul freight train in China. A $15 \mathrm{kPa}$ initial static deviator stress $\left(\sigma_{\mathrm{si}}\right)$ was applied prior to the application of $\sigma_{\mathrm{d}}$ [42], to simulate the vertical stress resulted by the rail, sleeper, and ballast. More detailed introduction regarding the test method and procedures can refer to the study of $\mathrm{Xu}$ et al. [37]. Figure 4 presents the schematic dynamic loading curve applied in the cyclic triaxial tests. The tests were terminated when the specimens were destroyed or the $\varepsilon_{\mathrm{s}}$ was achieved. Based on a few preliminary tests, the specimen was considered to be destroyed when the accumulative plastic strain reached $15 \%$, and when the accumulative plastic strain was lower than $10 \%$ and its increment within $2 \mathrm{~h}$ was less than $1 \mathrm{~mm}$, the specimen was deemed to attain a shakedown state in which the further plastic strain increments are negligible.

Table 1. Detailed program of cyclic triaxial tests.

\begin{tabular}{cccc}
\hline Group & $\boldsymbol{w}(\mathbf{\%})$ & $\sigma_{3} \mathbf{( k P a )}$ & $\sigma_{\mathbf{d}}(\mathbf{k P a})$ \\
\hline 1 & $9.3\left(S_{\mathrm{r}}=100 \%\right)$ & 15 & $50,100,125,150,200,250$ \\
2 & $9.3\left(S_{\mathrm{r}}=100 \%\right)$ & 30 & $50,100,125,150,200,250$ \\
3 & $9.3\left(S_{\mathrm{r}}=100 \%\right)$ & 60 & $50,100,125,150,200,250$ \\
4 & $6.2\left(S_{\mathrm{r}}=79.4 \%\right)$ & 15 & $100,150,200$ \\
5 & $6.2\left(S_{\mathrm{r}}=79.4 \%\right)$ & 30 & $250,275,300$ \\
6 & $6.2\left(S_{\mathrm{r}}=79.4 \%\right)$ & 60 & $250,300,350,400$ \\
\hline
\end{tabular}

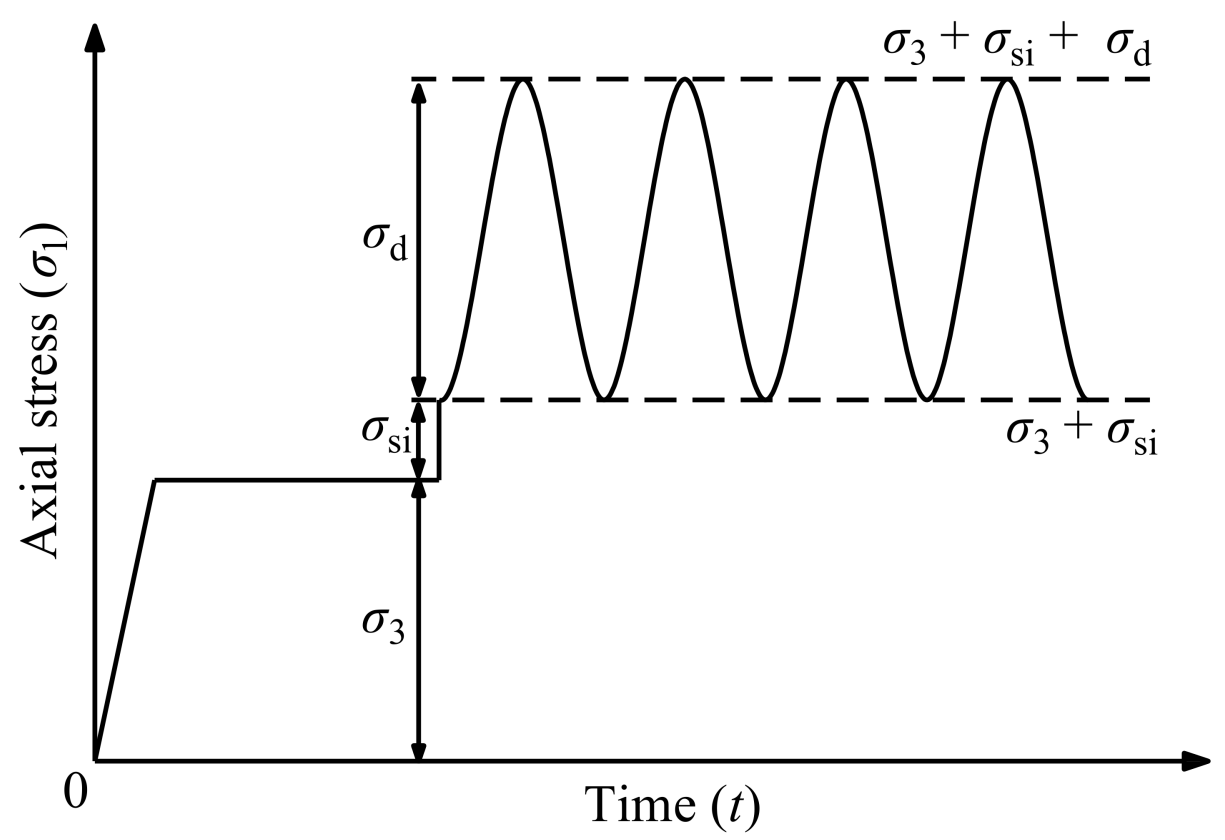

Figure 4. Cyclic loading curve [16,37].

\section{Results and Discussion of Accumulative Plastic Strain Curves}

Figures 5 and 6 present the variation curves of the accumulative plastic strain $\varepsilon_{\mathrm{p}}$ with cycle number $N$ of saturation and optimal moisture content specimens, respectively, where different curves correspond to different $\sigma_{\mathrm{d}}$. 


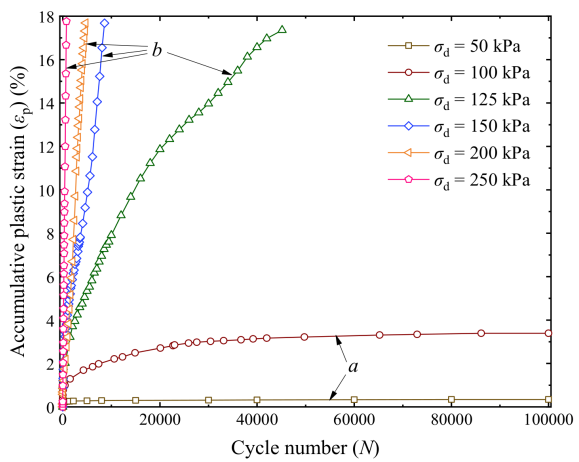

(a)

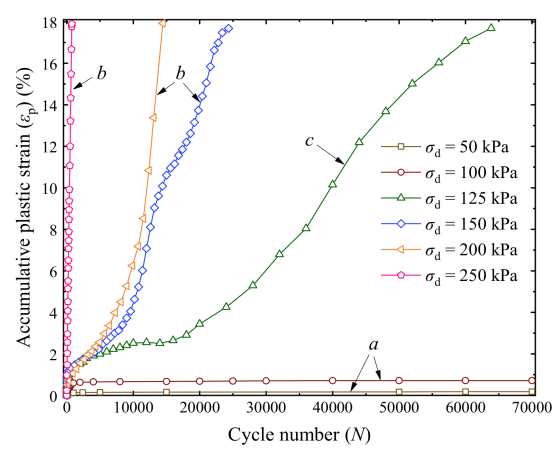

(b)

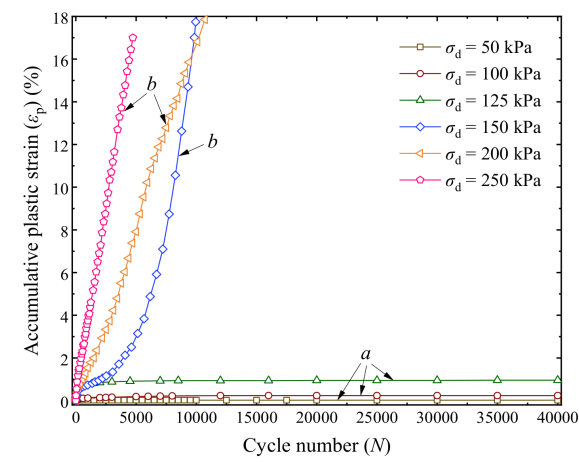

(c)

Figure 5. $\varepsilon_{\mathrm{p}}-N$ relationship of saturation specimens: (a) $\sigma_{3}=15 \mathrm{kPa} ;(\mathbf{b}) \sigma_{3}=30 \mathrm{kPa}$; (c) $\sigma_{3}=60 \mathrm{kPa}[16]$.

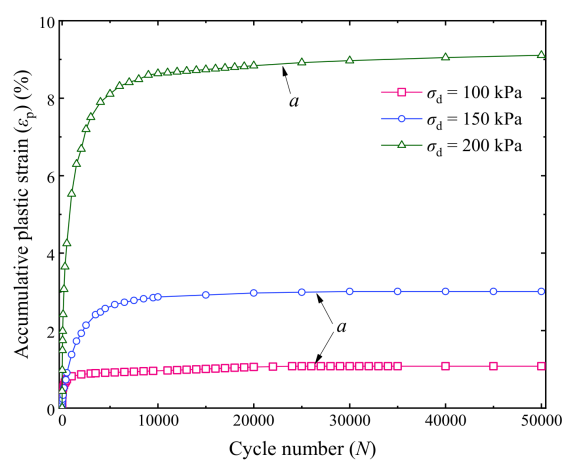

(a)

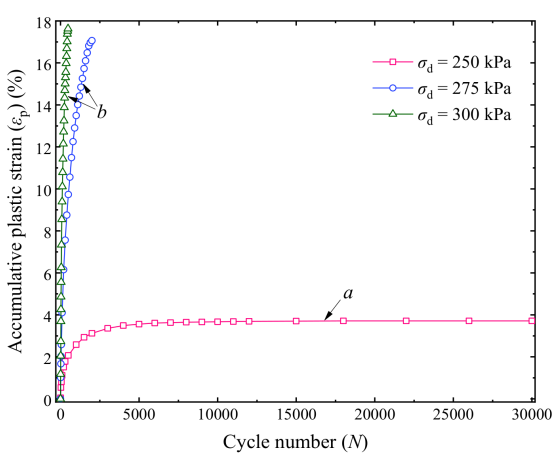

(b)

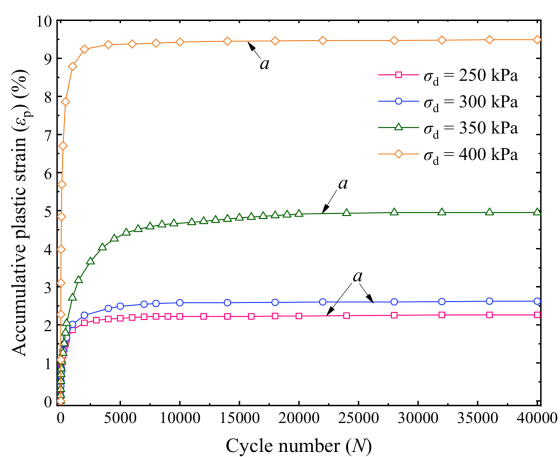

(c)

Figure 6. $\varepsilon_{\mathrm{p}}-N$ relationship of specimens with optimal moisture content: (a) $\sigma_{3}=15 \mathrm{kPa} ;(\mathbf{b}) \sigma_{3}=30 \mathrm{kPa} ;(\mathbf{c}) \sigma_{3}=60 \mathrm{kPa}$.

It can be observed that the $\varepsilon_{\mathrm{p}}$ and its rate decline with an increase in $\sigma_{3}$ but increase with the increase in $\sigma_{\mathrm{d}}$. Hence, the confining pressure and dynamic deviator stress have significant impacts on the development of $\varepsilon_{\mathrm{p}}$ of the UGM. The values of $\varepsilon_{\mathrm{p}}$ are generally greater than those reported in the existing literature [46-49]. One possible reason is that the tested confining pressures are relatively small comparing with existing studies. The low confining pressures tested in the present study can appropriately simulate the stress states of the subgrade soils in the field. The confining pressure of the subgrade soils can be approximately estimated as

$$
\sigma_{3}=K_{0}\left(\sigma_{s i}+\gamma h\right)
$$

where $K_{0}$ is the coefficient of lateral earth pressure and a value of 0.8 is generally adopted [58], $\gamma$ is the unit weight of the subgrade soil and a value of $22 \mathrm{kN} / \mathrm{m}^{3}$ is generally acceptable, and $h$ is the depth. The subgrade bed layers of a railway embankment generally have a thickness of $2.5 \mathrm{~m} \mathrm{[42].} \mathrm{As} \mathrm{a} \mathrm{result,} \mathrm{the} \mathrm{confining} \mathrm{pressure} \mathrm{of} \mathrm{the} \mathrm{subgrade} \mathrm{bed} \mathrm{layers} \mathrm{is}$ generally within the range of $12-56 \mathrm{kPa}$. Therefore, the confining pressures of 15,30 , and $60 \mathrm{kPa}$ were selected to simulate the stress states of the UGM in the field.

Based on the variation tendencies of the accumulative plastic strains in Figures 5 and 6, the $\varepsilon_{\mathrm{p}}$ versus $N$ curves can be divided into three types, i.e., the stable (class a), failure (class b), and critical (class c) patterns. A stable pattern represents that the growth rate of $\varepsilon_{\mathrm{p}}$ gradually attenuates and finally ceases with the increase in loading cycles. Because of the internal erosion behavior, the fine particles can provide lateral support for the coarse particles, which leads to local particle rearrangement under dynamic loading and compression of the intergranular void [50,59], thus a densification effect would be formed. Finally, a stable UGM specimen enters a dense state in which it can resist the damage effects of the cyclic loading, and no further plastic strain is produced in subsequent loading cycles. By contrast, a failure pattern illustrates that the accumulative plastic strain of the specimen 
continuously rapidly increases to a $\varepsilon_{\mathrm{p}}$ value greater than $15 \%$ within small loading cycles or collapses under $\sigma_{\mathrm{d}}$. In addition, the $\varepsilon_{\mathrm{p}}$ versus $N$ curve of a critical specimen is between the stable and failure patterns, of which the increase tendency of the accumulative plastic strain fluctuates and presents uncertainties with increasing the loading cycles. The dynamic deviator stress with respect to the critical curve pattern is generally designated as the critical dynamic stress $\sigma_{\text {cri }}$ of an UGM.

\section{Evaluation of Critical Dynamic Stress and Final Accumulative Plastic Strain}

4.1. Evaluation of Critical Dynamic Stress

4.1.1. Grey Relation of $\varepsilon_{\mathrm{p}}-N$ Curve Pattern Regarding $w, \sigma_{3}$, and $\sigma_{\mathrm{d}}$

It can be seen that the $\varepsilon_{\mathrm{p}}$ versus $N$ curve pattern of the UGM is greatly affected by the dynamic deviator stress $\sigma_{\mathrm{d}}$, confining pressure $\sigma_{3}$, and moisture content $w$, as presented in Figures 5 and 6 . In this section, the grey correlation theory was used to investigate the correlation degree of $\varepsilon_{\mathrm{p}}-N$ curve patterns in regard to the $\sigma_{\mathrm{d}}, \sigma_{3}$, and $w$.

Generally, principal component, regression, and variance analyses are commonly used to analyze systems. However, strict requirements should be met when using these methods, including (1) samples to obey typical probability distributions, (2) large size samples to ensure reliable analyses, and (3) a mass of calculations; moreover, the results between the qualitative and quantitative analyses are inconsistent at times, thereby occasionally leading to unreliable conclusions [60]. While the GRA is an advanced system analysis method and extensively employed in medical, economic, engineering, educational, and environmental fields to determine whether data sequences of a system have strong correlations. The method can effectively evaluate systems with small size data, where traditional statistical methods are unsuitable, because small size samples usually involve a great deal of grey information. Furthermore, the GRA has strong nonlinear fitting ability and convenient programming function [61]. The method can determine whether data sequences have strong correlations by comparing the similarity of their geometric curves, and greater similarities imply larger grey relational grades. The GRA does not have traditional demands on data distribution and can evaluate small size samples effectively, which would not generate disagreements between qualitative and quantitative results [60]. A brief introduction regarding the analysis steps of the GRA is as follows:

To perform GRA conveniently, non-dimensional treatment of the feature sequence $\left(Y=\left(y_{1}, y_{2}, y_{3}, \ldots, y_{\mathrm{n}}\right)\right)$ and observation sequences $\left(X_{i}=\left(x_{i 1}, x_{i 2}, x_{i 3}, \ldots, x_{i n}\right), i=1,2,3\right.$, $\ldots, m)$ is carried out by normalizing the sequences using the initial values as

$$
\begin{aligned}
X_{i}^{\prime}=X_{i} / x_{i 1} & =\left(x_{i 1}^{\prime}, x_{i 2}^{\prime}, x_{i 3}^{\prime}, \ldots x_{i n}^{\prime}\right), i=1,2,3, \ldots m \\
Y^{\prime} & =Y / y_{1}=\left(y_{1}^{\prime}, y_{2}^{\prime}, y_{3}^{\prime}, \ldots y_{n}^{\prime}\right)
\end{aligned}
$$

The grey correlation coefficient $\left(\gamma_{i j}, i=1,2,3, \ldots m, j=1,2,3, \ldots, n\right)$ between $y_{j}$ and $x_{i j}$ is calculated as

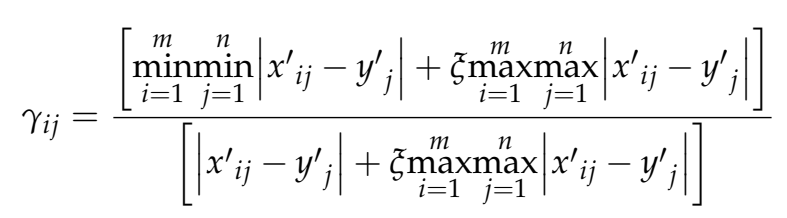

where $\xi$ denotes a discriminant coefficient within the range of 0 to 1 , and generally the value of $\xi$ is taken as $0.5[60,62-64]$. The grey relational grade $\left(\gamma_{i}\right)$ between $Y$ and $X_{i}$ is formulated as

$$
\gamma_{i}=\frac{1}{n} \sum_{j=1}^{n} \gamma_{i j}
$$

In this study, the sequence composed of the values of an index parameter $(\beta)$ that denoting the $\varepsilon_{\mathrm{p}}$ versus $N$ curve pattern was designated as the feature sequence $Y_{1}$, where $\beta$ values of 1.0, 2.0, and 3.0 were allotted to the stable, critical, and failure patterns, re- 
spectively, according to the recommendations of Javed et al. [65], Wu et al. [66], and Liu et al. [67]. In addition, the data sequences composed of moisture content $w$, confining pressure $\sigma_{3}$, and dynamic deviator stress $\sigma_{\mathrm{d}}$ are termed as the observation sequences $X_{1}$, $X_{2}$, and $X_{3}$, respectively. The computed values of the grey correlation coefficients $\gamma_{1 j}$, $\gamma_{2 j}$, and $\gamma_{3 j}$ are presented in Table 2 , and the grey relational grades $\left(\gamma_{1}, \gamma_{2}\right.$, and $\left.\gamma_{3}\right)$ of $\beta$ regarding $w, \sigma_{3}$, and $\sigma_{\mathrm{d}}$ obtained by Equation (5) are $0.809,0.745$, and 0.720 , respectively. Generally, the feature sequence is considered to be strongly correlated with the observation sequences if the calculated grey relational grade exceeds 0.6 , as recommended by previous studies $[62-64,68]$. Therefore, it is considered that $\beta$ (i.e., the curve pattern) is closely related to $w, \sigma_{3}$, and $\sigma_{\mathrm{d}}$. In addition, slight differences appear among $\gamma_{1}, \gamma_{2}$, and $\gamma_{3}$, implying that $w, \sigma_{3}$, and $\sigma_{\mathrm{d}}$ have approximate importance degree on determining the $\varepsilon_{\mathrm{p}}$ versus $N$ curve patterns of the UGM.

Table 2. Grey relational coefficients of $\beta$ with respect to $w, \sigma_{3}$, and $\sigma_{\mathrm{d}}$.

\begin{tabular}{|c|c|c|c|c|c|c|}
\hline$B$ & $\sigma_{3}(\mathbf{k P a})$ & $\sigma_{\mathrm{d}}(\mathbf{k P a})$ & $w(\%)$ & $\gamma_{1 j}$ & $\gamma_{2 j}$ & $\gamma_{3 j}$ \\
\hline 1 & 15 & 50 & 9.3 & 1.000 & 1.000 & 1.000 \\
\hline 1 & 15 & 100 & 9.3 & 1.000 & 1.000 & 0.778 \\
\hline 3 & 15 & 125 & 9.3 & 0.636 & 0.636 & 0.875 \\
\hline 3 & 15 & 150 & 9.3 & 0.636 & 0.636 & 1.000 \\
\hline 3 & 15 & 200 & 9.3 & 0.636 & 0.636 & 0.778 \\
\hline 3 & 15 & 250 & 9.3 & 0.636 & 0.636 & 0.636 \\
\hline 1 & 30 & 50 & 9.3 & 1.000 & 0.778 & 1.000 \\
\hline 1 & 30 & 100 & 9.3 & 1.000 & 0.778 & 0.778 \\
\hline 2 & 30 & 125 & 9.3 & 0.778 & 1.000 & 0.875 \\
\hline 3 & 30 & 150 & 9.3 & 0.636 & 0.778 & 1.000 \\
\hline 3 & 30 & 200 & 9.3 & 0.636 & 0.778 & 0.778 \\
\hline 3 & 30 & 250 & 9.3 & 0.636 & 0.778 & 0.636 \\
\hline 1 & 60 & 50 & 9.3 & 1.000 & 0.538 & 1.000 \\
\hline 1 & 60 & 100 & 9.3 & 1.000 & 0.538 & 0.778 \\
\hline 1 & 60 & 125 & 9.3 & 1.000 & 0.538 & 0.700 \\
\hline 3 & 60 & 150 & 9.3 & 0.636 & 0.778 & 1.000 \\
\hline 3 & 60 & 200 & 9.3 & 0.636 & 0.778 & 0.778 \\
\hline 3 & 60 & 250 & 9.3 & 0.636 & 0.778 & 0.636 \\
\hline 1 & 15 & 100 & 6.2 & 0.913 & 1.000 & 0.778 \\
\hline 1 & 15 & 150 & 6.2 & 0.913 & 1.000 & 0.636 \\
\hline 1 & 15 & 200 & 6.2 & 0.913 & 1.000 & 0.538 \\
\hline 1 & 30 & 250 & 6.2 & 0.913 & 0.778 & 0.467 \\
\hline 3 & 30 & 275 & 6.2 & 0.600 & 0.778 & 0.583 \\
\hline 3 & 30 & 300 & 6.2 & 0.600 & 0.778 & 0.538 \\
\hline 1 & 60 & 250 & 6.2 & 0.913 & 0.538 & 0.467 \\
\hline 1 & 60 & 300 & 6.2 & 0.913 & 0.538 & 0.412 \\
\hline 1 & 60 & 350 & 6.2 & 0.913 & 0.538 & 0.368 \\
\hline 1 & 60 & 400 & 6.2 & 0.913 & 0.538 & 0.333 \\
\hline 1 & 15 & 50 & 9.3 & 1.000 & 1.000 & 1.000 \\
\hline 1 & 15 & 100 & 9.3 & 1.000 & 1.000 & 0.778 \\
\hline
\end{tabular}

4.1.2. Analysis of Specimen Pattern using the BP Neural Network

Most existing empirical models for the critical dynamic stress and cumulative plastic strain of subgrade soils are based on explicit analyses of limited test results. However, the $\sigma_{\text {cri }}$ and $\varepsilon_{\mathrm{s}}$ of an UGM may have considerable non-linear correlations with influencing factors such as the $w, \sigma_{3}$, and $\sigma_{\mathrm{d}}$, and the correlations are generally difficult to be identified by explicit analyses of the test results. In this study, the BP neural network was used to analyze the specimen pattern based on the MATLAB (version R2018b) platform. The MATLAB is a powerful and high-performance programming tool for technical computation, which integrates computation, visualization, and programming in a user-friendly environment [69]. The BP neural network generally consists of an input layer, several hidden layers, and an output layer, which exhibits strong non-linear mapping functions 
on multi parameters. Consequently, the BP neural network is appropriate for analyzing the $\sigma_{\text {cri }}$ and $\varepsilon_{S}$ of the UGM, and the developed empirical model is considered capable to effectively reflect the relationships of $\sigma_{\text {cri }}$ and $\varepsilon_{\mathrm{s}}$ in regard to the $\sigma_{3}$ and $\sigma_{\mathrm{d}}$.

The BP neural network used in this study is a special machine learning method which focuses on intelligent predictions rather than improvements of computer algorithms, therefore the required amount of training data can be less than the traditional machine learning techniques, and a few studies have shown that training data with a size around 20 can yield acceptable training results [70-74]. The present study performed 28 cyclic triaxial tests on the UGM. Figure 7 presents a topological graph of a BP neural network that includes a hidden layer, in which the numbers of neurons in the input, hidden, and output layers are denoted by $A, B$, and $C$, respectively. The neurons in the input layer are specified as $w, \sigma_{3}$, and $\sigma_{\mathrm{d}}$, while the neuron in the output layer is specified as the index parameter $\beta$, therefore $A=3$ and $C=1$ in the present study.

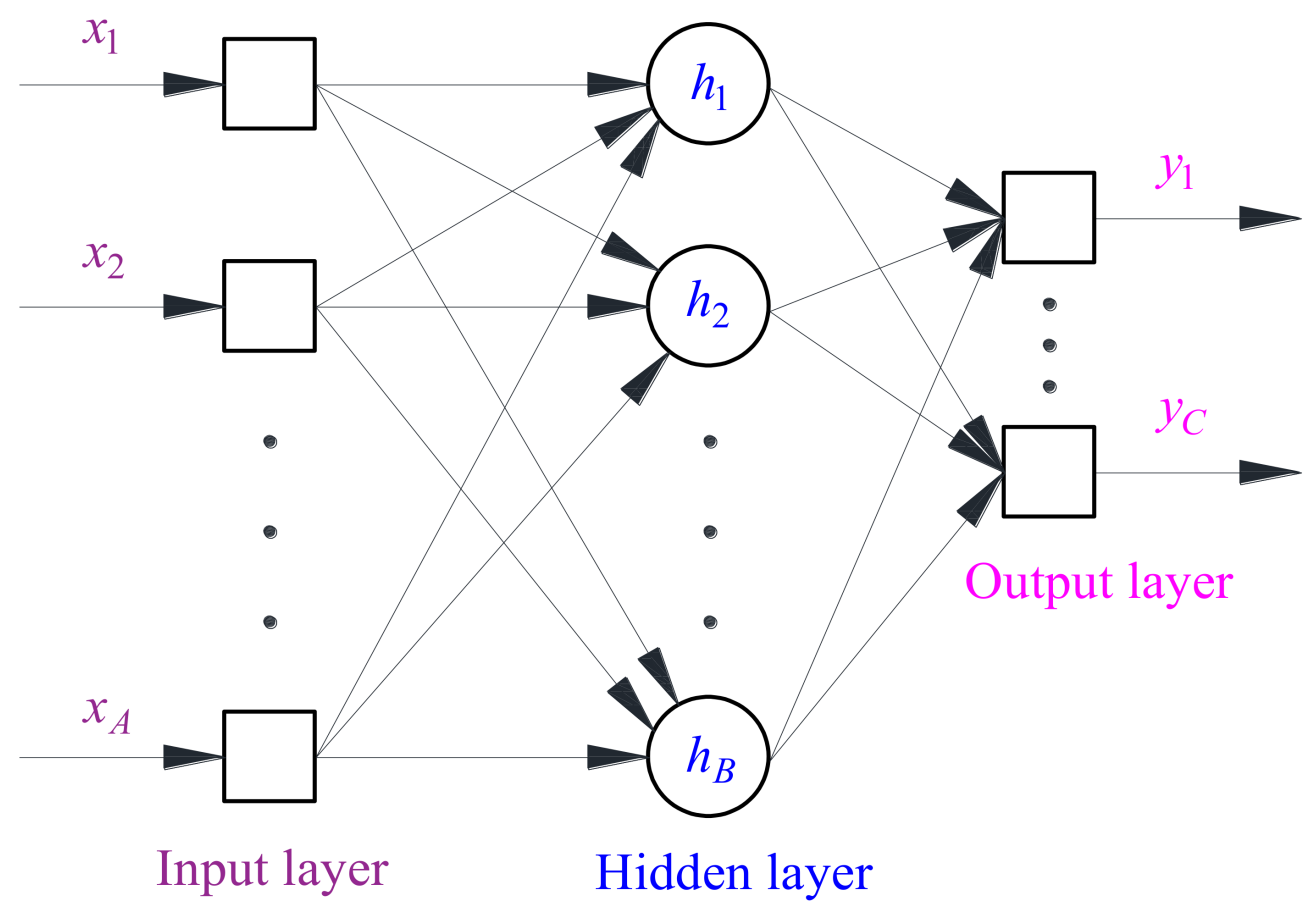

Figure 7. Topological graph of the BP neural network [16].

When the neurons in the input layer are assigned a data set regarding the $w, \sigma_{3}$, or $\sigma_{\mathrm{d}}$, the neurons in the hidden and output layer(s) will generate values by following a transfer function, and the yielded values of the neuron in the output layer are the evaluated values of $\beta$. In the self-training of a BP neural network, the yielded values in the output layer (i.e., the evaluated values of $\beta$ ) generally exhibit deviations in comparison to the theoretical values or expectations. In this study, the expectations of $\beta$ are 1.0, 2.0, and 3.0 regarding the stable, critical, and failure specimens, respectively. By inputting a series of data sets that correspond to different test conditions of $w, \sigma_{3}$, or $\sigma_{\mathrm{d}}$, the computation of the BP neural network continues until the sum of deviations meets the required precision or the iteration number achieves the maximum. In this study, a sigmoid function was adopted for the transfer function, and the maximum of iterations is 2000. For more details regarding BP neural networks, one can refer to Rumelhart et al. [75].

The number of neurons (i.e., the $B$ value) in the hidden layer(s) is one of the key parameters that could considerably affect the trained neural network. Chen et al. [76] stated that the value range of $B$ can be estimated as 


$$
B=\sqrt{A+B}+S
$$

where $S$ is a constant that ranges between 1 and 10. The value range of $B$ calculated by Equation (6) is 3-12. The mean square errors (MSE) of the trained BP neural network regarding the variation of parameter $B$ are presented in Figure 8, where the results showed that the MSE attained the minimum value when $B=3$, thus three neurons in the hidden layer were adopted in the following analyses.

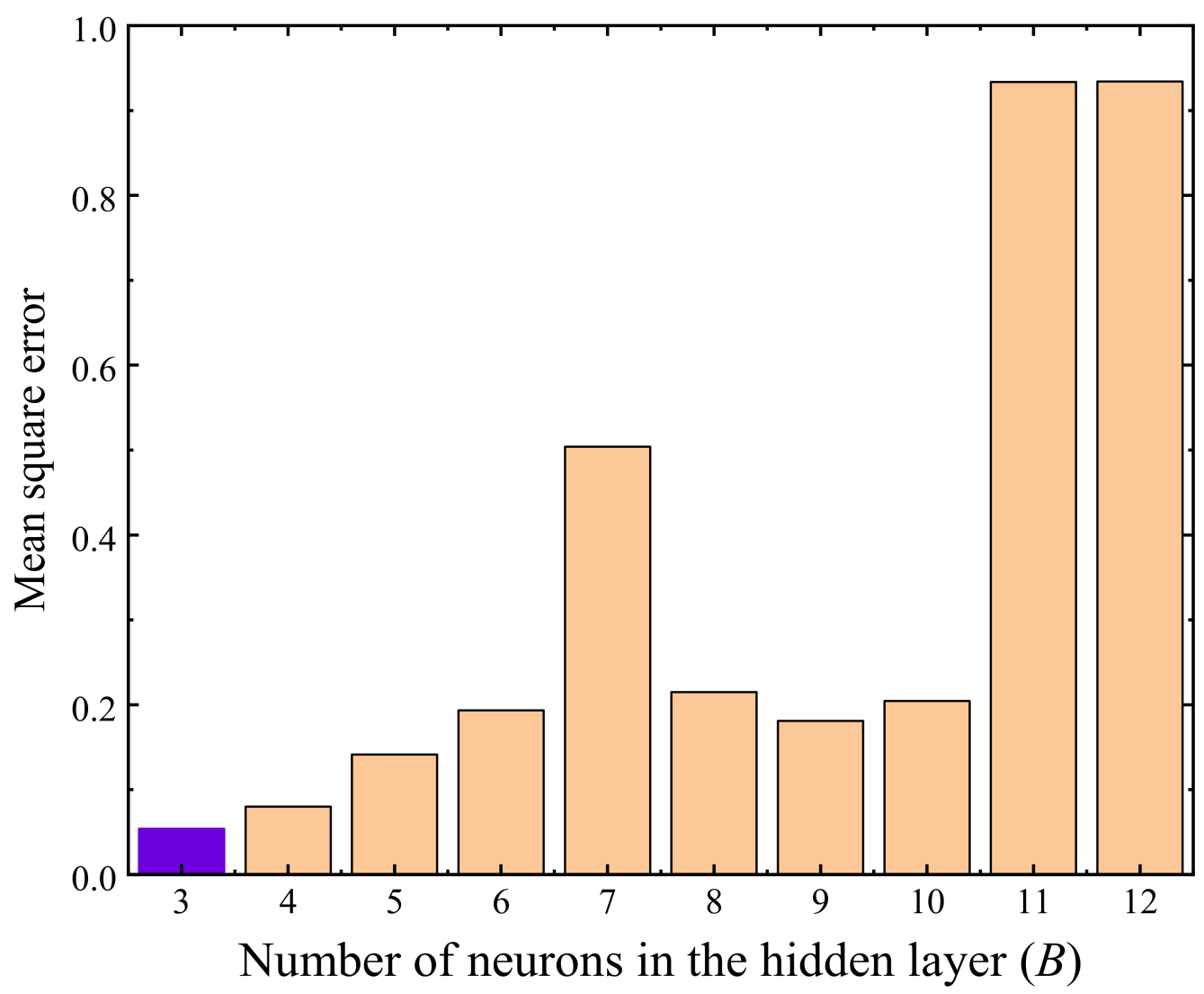

Figure 8. Mean square error with different $B$ values (regarding the $\sigma_{\text {cri }}$ ).

In training of the BP neural network, a stable specimen with test conditions of $w=6.2 \%$, $\sigma_{3}=60 \mathrm{kPa}$, and $\sigma_{\mathrm{d}}=350 \mathrm{kPa}$ (corresponding to a $\beta$ value of 1.0) and a failure specimen with conditions of $w=9.3 \%, \sigma_{3}=60 \mathrm{kPa}$, and $\sigma_{\mathrm{d}}=200 \mathrm{kPa}$ (corresponding to a $\beta$ value of 3.0) were excluded, which were used to verify the reliability of the trained BP neural network later on. Figure 9 presents the output of the trained optimal neural network using the remaining data (including the data of stable, failure, and critical specimens). The figure shows that the evaluated $\beta$ values are close to theoretical values without data distortion or local minimum problems, and the predicted $\beta$ values of the two specimens used to verify the trained neural network (data points in the rectangles) also agree well with the theoretical values, indicating that the trained optimal neural network is of acceptable reliability.

\subsubsection{Evaluation of Critical Dynamic Stress Using the Trained BP Neural Network}

Evaluations of the $\sigma_{\text {cri }}$ under different $\sigma_{3}$ were implemented using the trained optimal $\mathrm{BP}$ neural network. Predetermined moisture contents and confining pressures were first input as the neuro values in the input layer. Then, the input neuron value with respect to $\sigma_{\mathrm{d}}$ is continuously changed until the $\beta$ obtains 2.0. The final input $\sigma_{\mathrm{d}}$ which generates a $\beta$ value of 2.0 is therefore the evaluated value of $\sigma_{\text {cri }}$ with respect to the input $w$ and $\sigma_{3}$. The 
input $\sigma_{3}$ is altered within $15-60 \mathrm{kPa}$ by a $5 \mathrm{kPa}$ interval, and the evaluated $\sigma_{\text {cri }}$ values using the BP neural network are presented in Table 3.

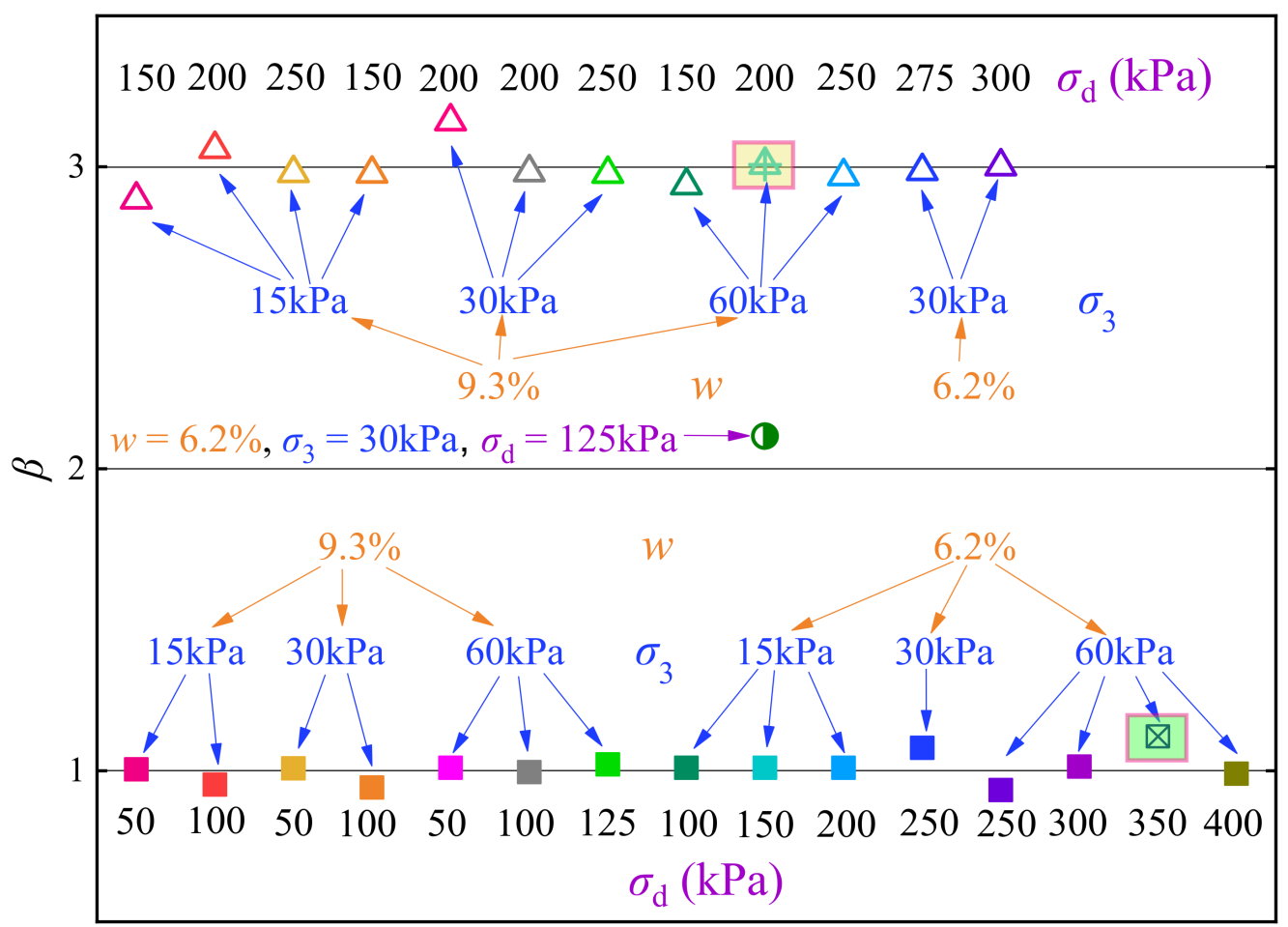

Figure 9. Output results of $\beta$ using the trained BP neural network.

Table 3. Evaluated critical dynamic stress.

\begin{tabular}{|c|c|c|c|c|c|c|c|c|c|c|c|}
\hline $\begin{array}{l}w \\
(\%)\end{array}$ & $\begin{array}{c}\sigma_{3} \\
(\mathbf{k P a})\end{array}$ & $\begin{array}{c}\sigma_{\text {cri }} \\
(\mathbf{k P a})\end{array}$ & $\begin{array}{l}w \\
(\%)\end{array}$ & $\begin{array}{c}\sigma_{3} \\
(\mathbf{k P a})\end{array}$ & $\begin{array}{c}\sigma_{\mathrm{cri}} \\
(\mathbf{k P a})\end{array}$ & $\begin{array}{l}w \\
(\%)\end{array}$ & $\begin{array}{c}\sigma_{3} \\
(\mathbf{k P a})\end{array}$ & $\begin{array}{c}\sigma_{\text {cri }} \\
(\mathbf{k P a})\end{array}$ & $\begin{array}{l}w \\
(\%)\end{array}$ & $\begin{array}{c}\sigma_{3} \\
(\mathbf{k P a})\end{array}$ & $\begin{array}{c}\sigma_{\mathrm{cri}} \\
(\mathbf{k P a})\end{array}$ \\
\hline \multirow{10}{*}{6.2} & 15 & 205 & \multirow{10}{*}{7.5} & 15 & 186 & \multirow{10}{*}{8.5} & 15 & 147 & \multirow{10}{*}{9.3} & 15 & 116 \\
\hline & 20 & 224 & & 20 & 203 & & 20 & 155 & & 20 & 119 \\
\hline & 25 & 248 & & 25 & 222 & & 25 & 165 & & 25 & 122 \\
\hline & 30 & 268 & & 30 & 242 & & 30 & 177 & & 30 & 125 \\
\hline & 35 & 295 & & 35 & 259 & & 35 & 185 & & 35 & 127 \\
\hline & 40 & 318 & & 40 & 277 & & 40 & 194 & & 40 & 130 \\
\hline & 45 & 345 & & 45 & 299 & & 45 & 204 & & 45 & 132 \\
\hline & 50 & 368 & & 50 & 319 & & 50 & 214 & & 50 & 135 \\
\hline & 55 & 390 & & 55 & 337 & & 55 & 223 & & 55 & 138 \\
\hline & 60 & 408 & & 60 & 357 & & 60 & 235 & & 60 & 140 \\
\hline
\end{tabular}

Variations of the evaluated $\sigma_{\text {cri }}$ of the UGM with the confining pressure are illustrated in Figure 10, with different lines corresponding to optimal and saturation moisture contents. It is found that the $\sigma_{\text {cri }}$ approximately linearly increases as the confining pressure increases, and the correlation between $\sigma_{\text {cri }}$ and $\sigma_{3}$ can be formulated as Equation (7), where $m$ and $n$ are fitting parameters. Therefore, it is a feasible method to improve the dynamic stability of a railway subgrade by appropriate techniques (e.g., the prestressed embankment technique [6]) to increase the confining pressure of the subgrade soil. Figure 10 indicates that the $\sigma_{\text {cri }}$ of the UGM is also influenced by the moisture content of the UGM. It is therefore considered that the model parameters $m$ and $n$ in Equation (7) could have correlations with the $w$, and Equation (7) can be reformulated as Equation (8), where $f_{1}(w)$ and $f_{2}(w)$ are functions of $w$. However, due to the limited moisture contents tested, the expressions 
of $f_{1}(w)$ and $f_{2}(w)$ are still not clear, and further investigations regarding this topic are desirable in future studies.

$$
\begin{gathered}
\sigma_{\text {cri }}=m \times \sigma_{3}+n \\
\sigma_{\text {cri }}=f_{1}(w) \times \sigma_{3}+f_{2}(w)
\end{gathered}
$$

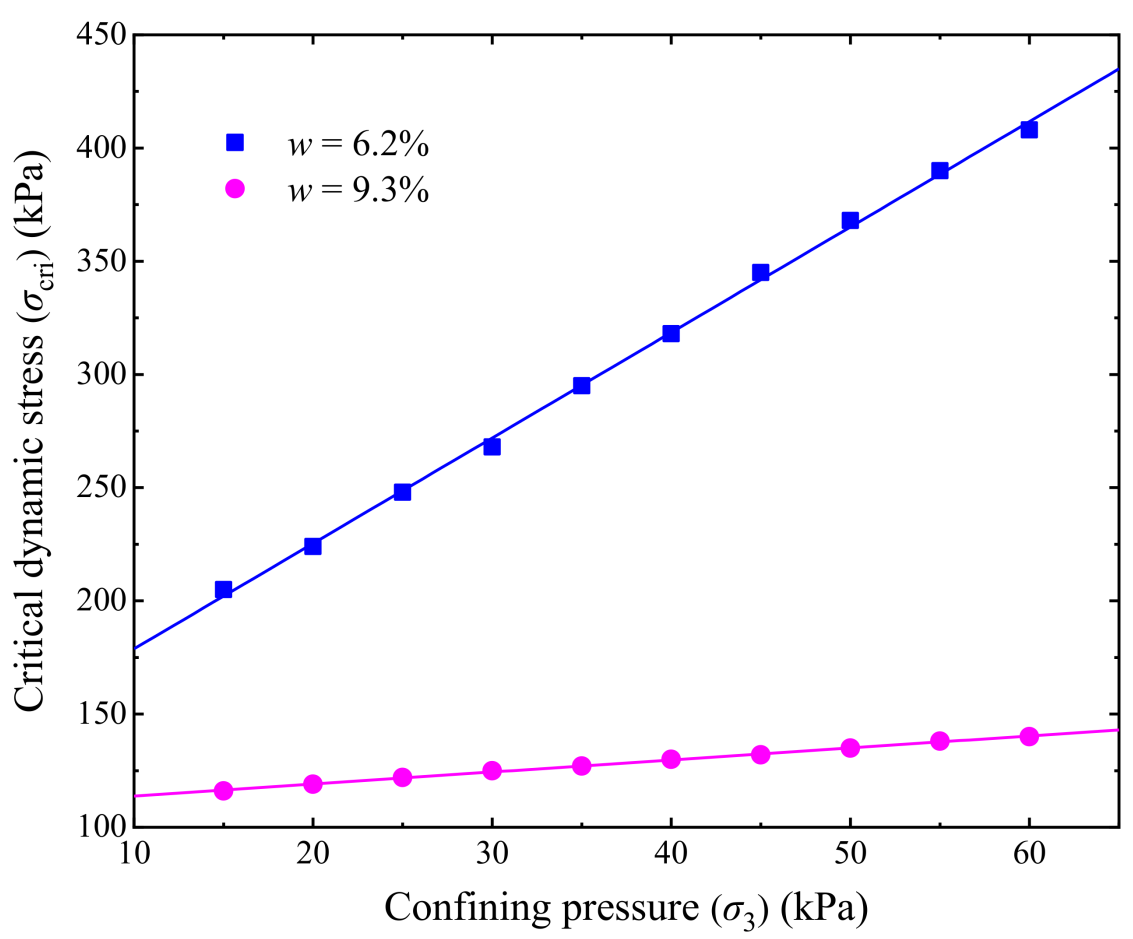

Figure 10. Relationship between critical dynamic stress and confining pressure.

Dawson et al. [77] reported that the critical total vertical stress $\left(\sigma_{1 \mathrm{~d}}\right.$, the sum of $\sigma_{\text {cri }}$ and $\sigma_{3}$ ) of unbound granular subgrade soils can be formulated as

$$
\sigma_{1 \mathrm{~d}}=A\left(\sigma_{1 \mathrm{~d}} / \sigma_{3}\right)^{B}
$$

where $A$ and $B$ are model parameters.

Wang et al. [78] performed cyclic triaxial tests on an UGM, having a similar gradation, of which both the fine contents (less than $0.075 \mathrm{~mm}$ ) of the materials tested by Wang et al. [78] and this study were around 10\%. Wang et al. [78] reported that the values of model parameters $A$ and $B$ are 3838.8 and -1.583 for the UGM. Based on Equation (9), it is deduced that the correlation between the $\sigma_{\text {cri }}$ and $\sigma_{3}$ of the UGM is as

$$
\sigma_{\text {cri }}=24.4123 \times \sigma_{3}^{0.6129}-\sigma_{3}
$$

The functional image of Equation (10) is presented in Figure 11. It is observed that the relationship between $\sigma_{\text {cri }}$ and $\sigma_{3}$ shows some non-linearity; however, the non-linearity is not discernible when the UGM is in a low confining pressure service state, and can be approximately replaced by a linear relationship with a high determination coefficient $\left(R^{2}\right)$ of 0.99, as illustrated in Figure 11. Therefore, it is rational to simplify a linear relationship between $\sigma_{\text {cri }}$ and $\sigma_{3}$ of an UGM used as subgrade material. 


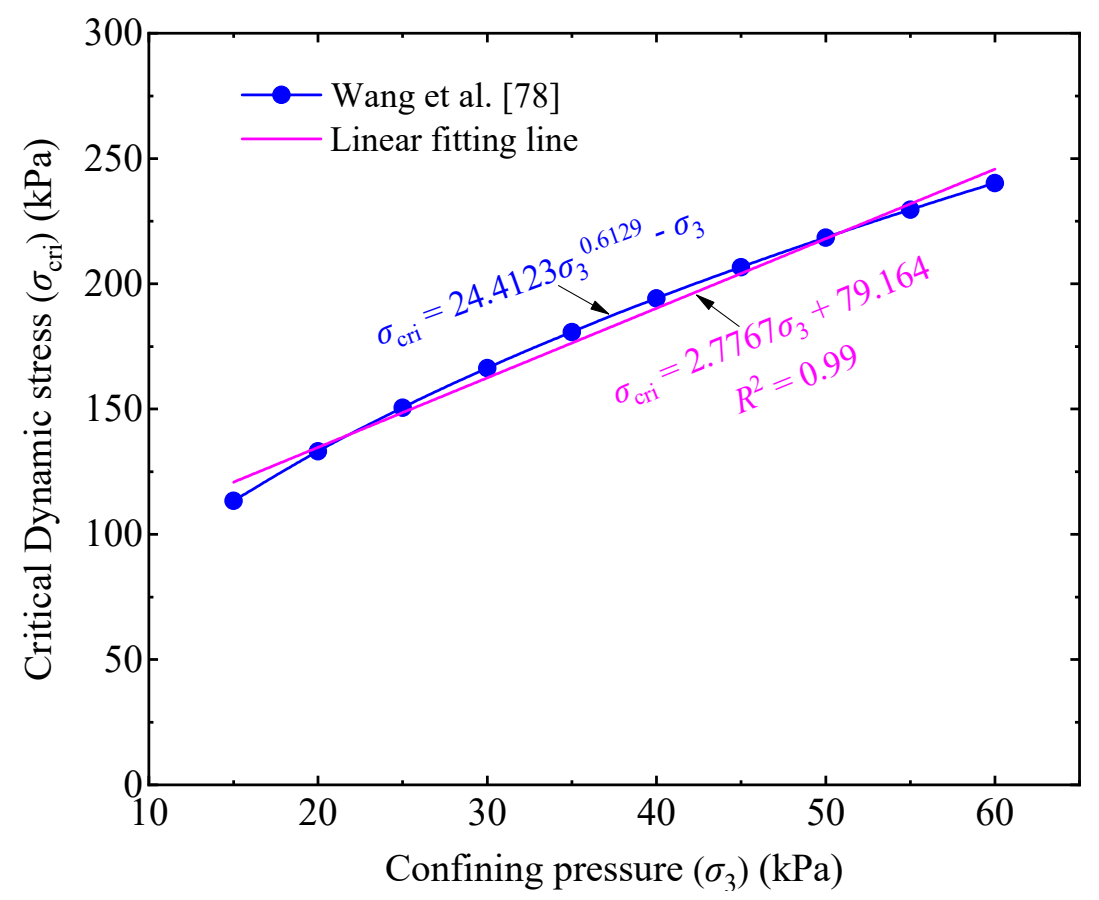

Figure 11. Relationships between $\sigma_{\text {cri }}$ and $\sigma_{3}$.

Figure 11. Relationships between $\sigma_{\text {cri }}$ and $\sigma_{3}$.

\subsection{Evaluation of Final Accumulative Plastic Strain}

4.2.1. Grey Relation of $\varepsilon_{\mathrm{S}}$ Regarding $w, \sigma_{3}$, and $\sigma_{\mathrm{d}}$

A railway generally has strict requirements on surface deformation; therefore, the failure and critical patterns of the UGM are generally not expected in engineering practice. Consequently, this section primarily focuses on evaluating the final accumulative plastic strain $\varepsilon_{\mathrm{s}}$ of stable specimens (i.e., the class a curves in Figures 5 and 6). The grey correlation theory was used to investigate the correlation degrees of $\varepsilon_{\mathrm{S}}$ in regard to $w, \sigma_{3}$, and $\sigma_{\mathrm{d}}$ by taking the sequence composed of final accumulative plastic $\varepsilon_{\mathrm{s}}$ as the feature sequence $Y_{2}$. The computed values of the grey correlation coefficients $\gamma_{1 j}^{\prime}, \gamma_{2 j}^{\prime}$, and $\gamma_{3 j}^{\prime}$ are presented in Table 4 , and the grey relational grades $\left(\gamma_{1}^{\prime}, \gamma_{2}^{\prime}\right.$, and $\left.\gamma_{3}^{\prime}\right)$ of $\varepsilon_{\mathrm{s}}$ regarding $w, \sigma_{3}$, and $\sigma_{\mathrm{d}}$ obtained by Equation (5) are 0.796, 0.733, and 0.724 (larger than 0.6), respectively; therefore, the $\varepsilon_{\mathrm{s}}$ is considered to be closely related to the $w, \sigma_{3}$, and $\sigma_{\mathrm{d}}$. Furthermore, slight differences appear among $\gamma_{1}^{\prime}, \gamma_{2}^{\prime}$, and $\gamma_{3}^{\prime}$, implying that $w, \sigma_{3}$, and $\sigma_{\mathrm{d}}$ have similar importance degree for the final accumulative plastic strain of the UGM. 
Table 4. Grey correlation coefficients of $\varepsilon_{\mathrm{s}}$ with respect to $w, \sigma_{3}$, and $\sigma_{\mathrm{d}}$.

\begin{tabular}{ccccccc}
\hline $\boldsymbol{\varepsilon}_{\mathbf{S}} \mathbf{( \% )}$ & $\sigma_{\mathbf{3}} \mathbf{( \mathbf { k P a } )}$ & $\boldsymbol{\sigma}_{\mathbf{d}} \mathbf{( \mathbf { k P a } )}$ & $\boldsymbol{w} \mathbf{( \% )}$ & $\boldsymbol{\gamma}_{\mathbf{1} \boldsymbol{j}}^{\prime}$ & $\boldsymbol{\gamma}^{\prime}{ }_{\mathbf{j}}$ & $\boldsymbol{\gamma}^{\prime}{ }_{\mathbf{j}}$ \\
\hline 0.34 & 15 & 50 & 9.3 & 1.000 & 1.000 & 1.000 \\
3.39 & 15 & 100 & 9.3 & 0.603 & 0.603 & 0.631 \\
0.18 & 30 & 50 & 9.3 & 0.967 & 0.903 & 0.967 \\
0.71 & 30 & 100 & 9.3 & 0.926 & 0.994 & 0.994 \\
0.02 & 60 & 50 & 9.3 & 0.935 & 0.776 & 0.935 \\
0.24 & 60 & 100 & 9.3 & 0.979 & 0.805 & 0.913 \\
0.96 & 60 & 125 & 9.3 & 0.882 & 0.921 & 0.977 \\
1.08 & 15 & 100 & 6.2 & 0.844 & 0.862 & 0.921 \\
3.01 & 15 & 150 & 6.2 & 0.625 & 0.634 & 0.699 \\
9.11 & 15 & 200 & 6.2 & 0.343 & 0.346 & 0.374 \\
3.71 & 30 & 250 & 6.2 & 0.571 & 0.605 & 0.697 \\
2.26 & 60 & 250 & 6.2 & 0.695 & 0.837 & 0.892 \\
2.62 & 60 & 300 & 6.2 & 0.659 & 0.786 & 0.889 \\
4.95 & 60 & 350 & 6.2 & 0.495 & 0.563 & 0.643 \\
9.49 & 60 & 400 & 6.2 & 0.333 & 0.363 & 0.406 \\
\hline
\end{tabular}

\subsubsection{Evaluation of Final Accumulative Plastic Strain Using the BP Neural Network}

The test data of stable specimens were used to perform the self-training of the BP neural network, excluding two specimens tested with conditions of $w=6.2 \%, \sigma_{3}=60 \mathrm{kPa}$, and $\sigma_{\mathrm{d}}=300 \mathrm{kPa}$ (corresponding to a $\varepsilon_{\mathrm{s}}$ value of $2.62 \%$ ) and $w=9.3 \%, \sigma_{3}=30 \mathrm{kPa}$, and $\sigma_{\mathrm{d}}=100 \mathrm{kPa}$ (corresponding to a $\varepsilon_{\mathrm{s}}$ value of $0.71 \%$ ), respectively, which were employed to verify the reliability of the trained BP neural network later on. The variation of the MSE of the trained BP neural network with the parameter $B$ is presented in Figure 12, where the results show that the hidden layer of the optimal BP neural network contains eight neurons. Figure 13 presents the evaluated $\varepsilon_{\mathrm{S}}$ values using the trained optimal neural network, showing that the final accumulative plastic strains generated by the BP neural network agree well with the measured data, and the predicted $\varepsilon_{\mathrm{S}}$ of the two specimens used to verify the trained neural network also close to the measured values (see the triangular points in Figure 13), indicating that the trained optimal BP neural network is of acceptable reliability.

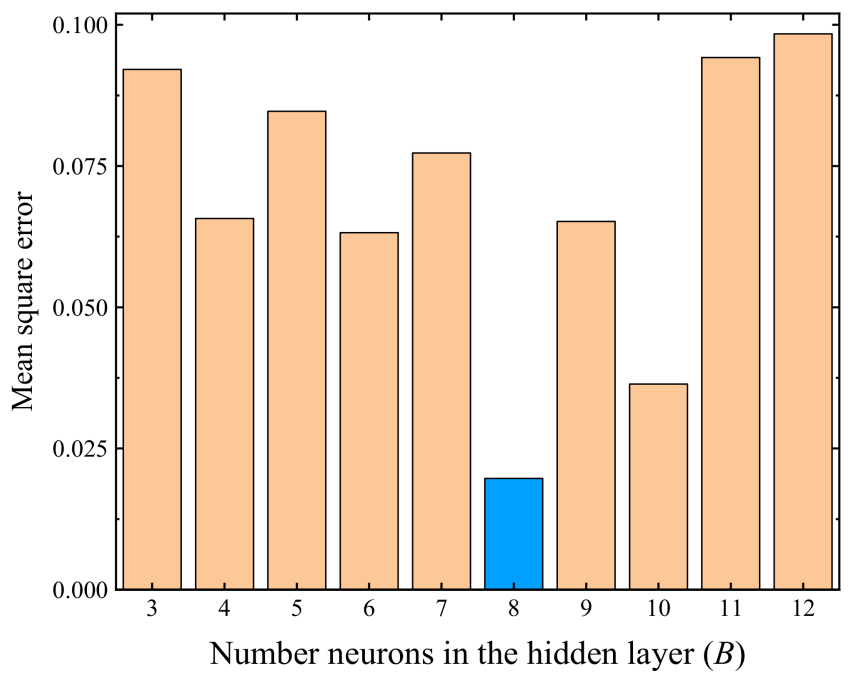

Figure 12. Mean square error with different $B$ values (regarding the $\varepsilon_{\mathrm{S}}$ ). 


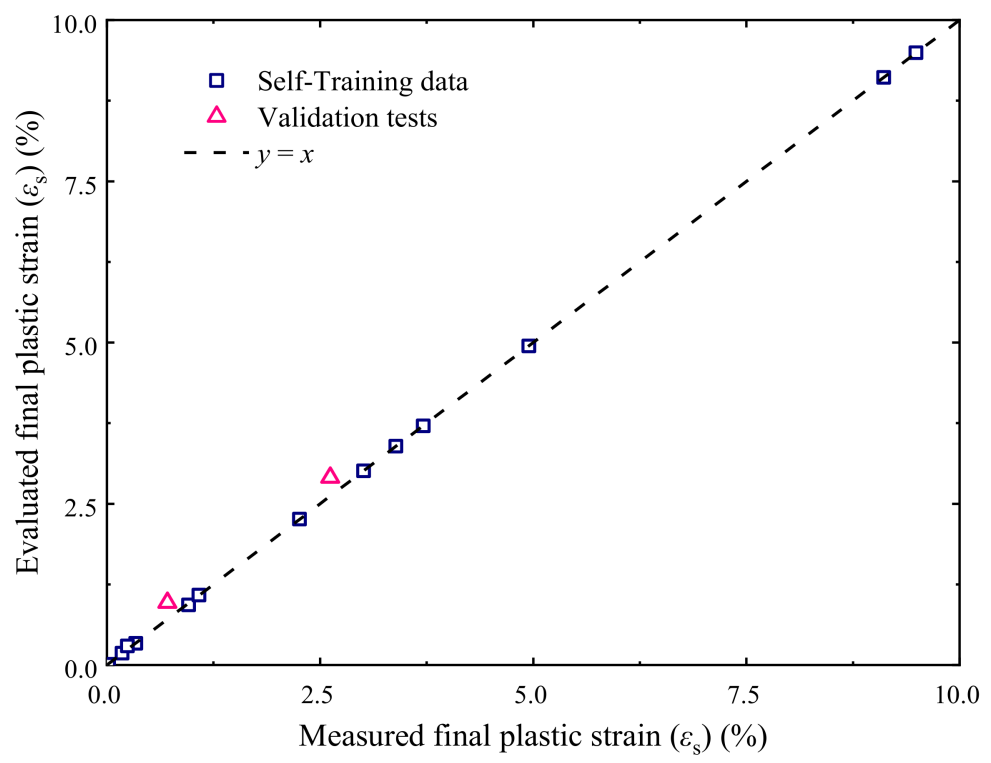

Figure 13. Output of $\varepsilon_{\mathrm{s}}$ using the optimal BP neural network.

The $\varepsilon_{\mathrm{S}}$ of the UGM under different $\sigma_{3}$ and $\sigma_{\mathrm{d}}$ can then be evaluated using the trained optimal BP neural network. The relationships of the predicted $\varepsilon_{\mathrm{s}}$ with respect to $\sigma_{\mathrm{d}}$ and $\sigma_{3}$ are presented in Figures 14 and 15, respectively. It can be found that $\varepsilon_{s}$ and its variation rate non-linearly increase with increasing $\sigma_{\mathrm{d}}$ but non-linearly decrease as $\sigma_{3}$ increases. Furthermore, the $\varepsilon_{\mathrm{S}}$ of saturation specimens with low confining pressures (e.g., $15 \mathrm{kPa}$ in Figure 14) starts to increase in a large rate when the dynamic deviator stress exceeds $60 \mathrm{kPa}$. Freight trains operated in the heavy-haul railway system of China can generally impose a maximum dynamic stress greater than $60 \mathrm{kPa}$ on the subgrade surface $[17,57,79,80]$. Therefore, keeping sufficient drainage capacity and preventing the subgrade approaching saturation are important in the routine maintenance of a railway. In addition, increasing the confining pressure can efficiently reduce the final accumulative plastic strain of the UGM, especially in low confining pressure conditions as illustrated in Figure 15.

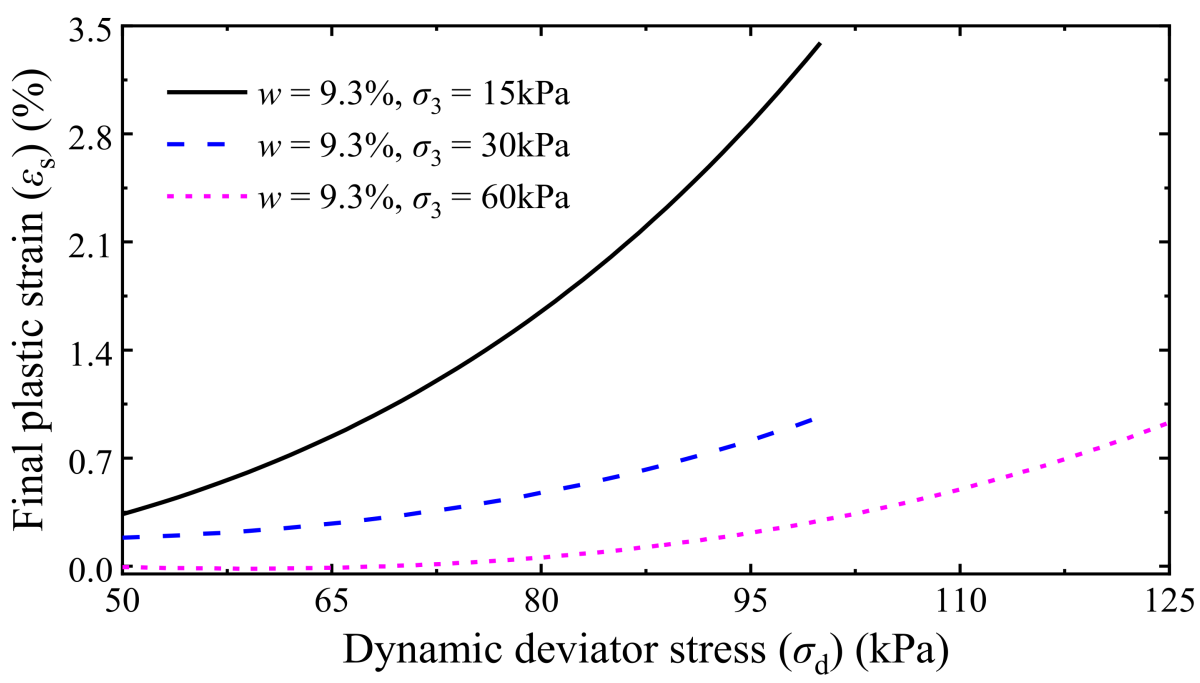

Figure 14. $\varepsilon_{\mathrm{s}}-\sigma_{\mathrm{d}}$ relationship of saturation specimens. 


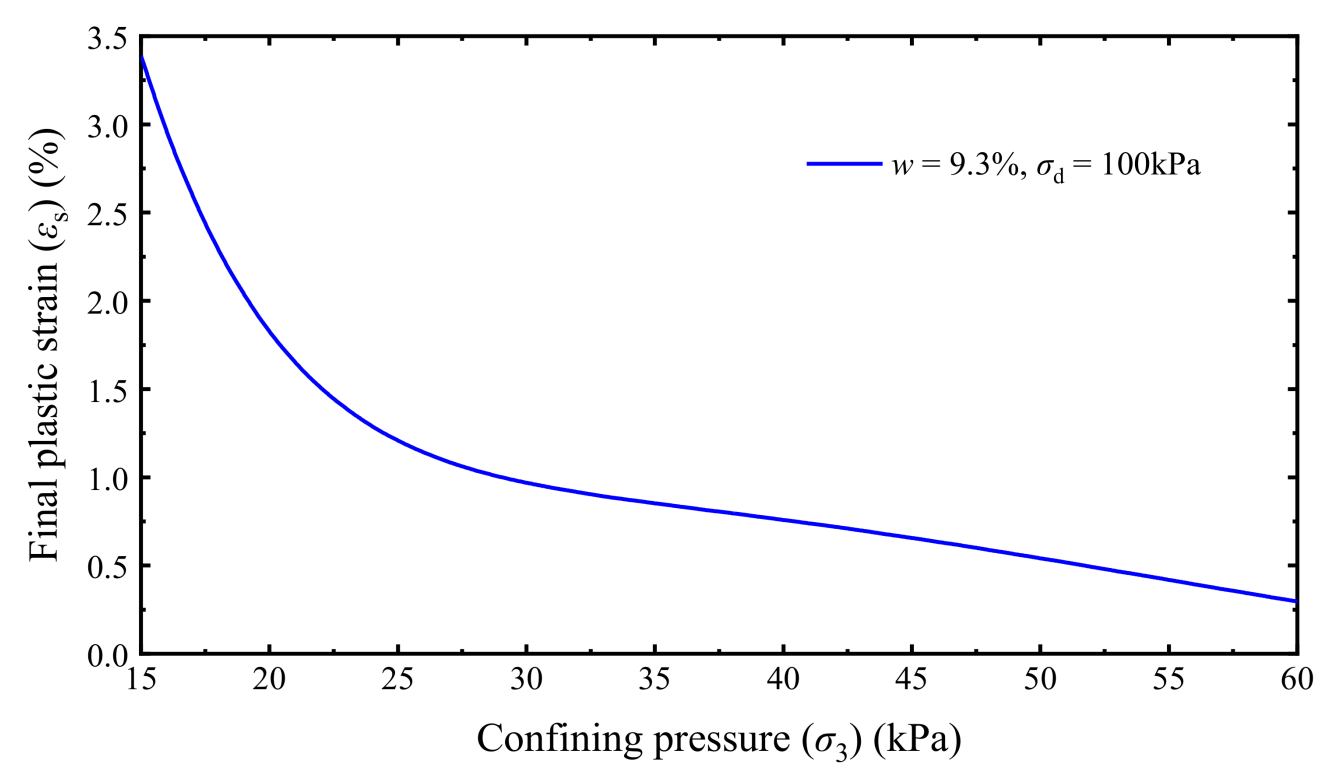

Figure 15. $\varepsilon_{\mathrm{s}}-\sigma_{3}$ relationship of saturation specimens.

\section{Conclusions}

The critical dynamic stress $\left(\sigma_{\text {cri }}\right)$ and accumulative plastic strain $\left(\varepsilon_{\mathrm{p}}\right)$ are primary indicators regarding the dynamic stability of unbound granular materials (UGMs). In this study, the dynamic stability of a typical UGM employed in railway subgrade bed construction was investigated by performing a series of large-scale cyclic triaxial tests, while considering the variations of moisture contents $(w)$, confining pressures $\left(\sigma_{3}\right)$, and dynamic deviator stresses $\left(\sigma_{\mathrm{d}}\right)$. A data processing method in combination with a back-propagation (BP) neural network is developed to analyze the test results, and an effective method is presented to evaluate the $\sigma_{\text {cri }}$ and the final $\varepsilon_{\mathrm{p}}\left(\varepsilon_{\mathrm{s}}\right)$ of the UGM. The main conclusions obtained are as follows:

- The variation curves of $\varepsilon_{\mathrm{p}}$ with cyclic number $(N)$ can be categorized into stable, failure, and critical patterns, and the grey relational analyses shown that the curve patterns and final accumulative plastic strain $\varepsilon_{\mathrm{S}}$ of stable specimens are closely related to the $w$, $\sigma_{3}$, and $\sigma_{\mathrm{d}}$. In addition, the analyzed grey relational grades were in a narrow range of 0.72 to 0.81 , demonstrating that the $w, \sigma_{3}$, and $\sigma_{\mathrm{d}}$ have similar importance degrees in determining the $\varepsilon_{\mathrm{p}}$ versus $N$ curve patterns and the values of $\varepsilon_{\mathrm{p}}$ of the UGM.

- The developed evaluation method indicates that the $\sigma_{\text {cri }}$ approximately linearly increases with increasing $\sigma_{3}$, and a simple linear empirical equation is proposed for the $\sigma_{\text {cri }}$. In addition, $\varepsilon_{\mathrm{s}}$ and its variation rate non-linearly increases with increasing $\sigma_{\mathrm{d}}$ but non-linearly decreases as $\sigma_{3}$ increases; therefore, an increase in $\sigma_{3}$ can effectively reduce the $\varepsilon_{\mathrm{S}}$, especially in low confining pressure conditions.

- The $\varepsilon_{\mathrm{s}}$ of saturation specimens with a low confining pressure of $15 \mathrm{kPa}$ started to increase rapidly when the $\sigma_{\mathrm{d}}$ was greater than $60 \mathrm{kPa}$ which is generally less than the dynamic deviator stress on subgrade surfaces imposed by freight trains operated in heavy-haul railway lines. Therefore, keeping sufficient drainage capacity, preventing the subgrade approaching saturation, and raising the confining pressure of the subgrade by appropriate reinforcement techniques are effective ways to enhance the railway dynamic stability.

Author Contributions: Conceptualization, F.X. and W.L.; methodology, F.X. and Q.Z.; software, B.Z. and J.D.; formal analysis, B.Z. and Q.Y.; writing-original draft, Q.Z. and J.D.; writing-review and editing, F.X. and Q.Y.; funding acquisition, W.L. and F.X.; supervision, W.L. All authors have read and agreed to the published version of the manuscript. 
Funding: The research was funded by the National Natural Science Foundation of China (No. 51978672) and the Research Project on Deepening Innovation and Entrepreneurship Education Reform of Central South University (No. 2020CG039).

Institutional Review Board Statement: Not applicable.

Informed Consent Statement: Not applicable.

Data Availability Statement: The data used to support the findings of this study are available from the corresponding author upon reasonable request.

Conflicts of Interest: The authors declare no conflict of interest.

\section{References}

1. Lin, P.Y.; Tang, L.S.; Ni, P.P. Field evaluation of subgrade soils under dynamic loads using orthogonal earth pressure transducers. Soil Dyn. Earthq. Eng. 2019, 121, 12-14. [CrossRef]

2. Saberian, M.; Li, J.; Setunge, J. Evaluation of permanent deformation of a new pavement base and subbase containing unbound granular materials, crumb rubber and crushed glass. J. Clean. Prod. 2019, 230, 38-45. [CrossRef]

3. Xiao, Y.J.; Zheng, K.Y.; Chen, L.X.; Mao, J.F. Shakedown analysis of cyclic plastic deformation characteristics of unbound granular materials under moving wheel loads. Constr. Build. Mater. 2018, 167, 457-472. [CrossRef]

4. Li, L.H.; Fang, Y.N.; Cheng, B.W.; Chen, N.; Tian, M.; Liu, Y.M. Characterisation of Geogrid and Waste Tyres as Reinforcement Materials in Railway Track Beds. Materials 2021, 14, 4162. [CrossRef] [PubMed]

5. Zhang, J.H.; Zhang, A.S.; Li, J.; Li, F.; Peng, J.H. Gray Correlation Analysis and Prediction on Permanent Deformation of Subgrade Filled with Construction and Demolition Materials. Materials 2019, 12, 3035. [CrossRef]

6. Xu, F.; Leng, W.M.; Nie, R.S.; Zhang, Q.S.; Yang, Q. New structure for strengthening soil embankments. Adv. Civ. Eng. 2018, 2018, 4809034. [CrossRef]

7. Ju, S.H.; Leong, C.C.; Ho, Y.S. Safety of maglev trains moving on bridges subject to foundation settlements and earthquakes. J. Bridge Eng. 2014, 19, 91-100. [CrossRef]

8. Remennikov, A.M.; Kaewunruen, S. A review of loading conditions for railway track structures due to train and track vertical interaction. Struct. Control Health 2008, 15, 207-234. [CrossRef]

9. Lyu, Z.; Qian, J.G.; Shi, Z.H.; Gao, Q. Dynamic responses of layered poroelastic ground under moving traffic loads considering effects of pavement roughness. Soil. Dyn. Earthq. Eng. 2020, 130, 105996. [CrossRef]

10. Dong, K.; Con1nolly, D.P.; Laghrouche, O.; Woodward, P.K.; Alves, C.P. The stiffening of soft soils on railway lines. Transp. Geotech. 2018, 17, 179-191. [CrossRef]

11. Puppala, A.J.; Saride, S.; Chomtid, S. Experimental and modeling studies of permanent strains of subgrade soils. J. Geotech. Geoenviron. 2009, 135, 1379-1389. [CrossRef]

12. Aw, E.S. Low Cost Monitoring System to Diagnose Problematic Rail Bed: Case Study at a Mud Pumping Site. Ph.D. Thesis, Massachusetts Institute of Technology, Cambridge, MA, USA, 2007.

13. Kang, X.; Ge, L.; Chang, K.T.; Kwok, A.O. Strain-controlled cyclic simple shear tests on sand with radial strain measurements. J. Mater. Civil. Eng. 2016, 28, 0405169. [CrossRef]

14. Zhang, Q.S.; Leng, W.M.; Xu, F.; Yang, Q.; Ai, X. Additional stress in soil embankments subjected to a new prestressed reinforcement device. J. Civ. Eng. Manag. 2019, 25, 700-714. [CrossRef]

15. Xiao, J.H.; Juang, C.H.; Xu, C.J.; Li, X.W.; Wang, L. Strength and deformation characteristics of compacted silt from the lower reaches of the Yellow River of China under monotonic and repeated loading. Eng. Geol. 2014, 178, 49-57. [CrossRef]

16. Zhai, B.; Leng, W.M.; Xu, F.; Zhang, S.; Ye, X.Y.; Leng, H.K. Critical dynamic stress and shakedown limit criterion of coarse-grained subgrade soil. Transp. Geotech. 2020, 23, 100354. [CrossRef]

17. Guo, Y.; Zhai, W.M. Long-term prediction of track geometry degradation in high-speed vehicle-ballastless track system due to differential subgrade settlement. Soil Dyn. Earthq. Eng. 2018, 113, 1-11. [CrossRef]

18. Nie, R.S.; Chen, Y.F.; Leng, W.M.; Yang, Q. Experimental measurement of dynamic load parameters for pier pile caps of high-speed railway bridges. Proc. Inst. Mech. Eng. Part F 2017, 231, 162-174. [CrossRef]

19. NRA (TB10621-2014). Code for Design of High Speed Railway; China Railway Publishing House: Beijing, China, 2014.

20. Atilla, M.A.; Afer, E. Undrained behavior of clay under cyclic shear stresses. J. Geotech. Eng. 1989, 115, 968-983.

21. Liu, J.K.; Xiao, J.H. Experimental study on the stability of railroad silt subgrade with increasing train speed. J. Geotech. Geoenviron. 2010, 136, 833-841. [CrossRef]

22. Sabine, W.; Dawson, A.R.; Frohmut, W. Permanent deformation behavior of granular materials and the shakedown concept. Transp. Res. Rec. 2001, 1757, 75-81.

23. Wang, T.L.; Liu, J.K.; Tian, Y.H. Dynamic properties of cement- and lime-improved soil subjected to freeze-thaw cycles. Chin. J. Geotech. Eng. 2010, 32, 1733-1737.

24. David, C.P.; Jalal, H.K. dynamic triaxial tests on remoulded clays. J. Geotech. Eng. 1984, 110, 1431-1445.

25. Cheung, L.W. Laboratory Assessment of Pavement Foundation Materials. Ph.D. Thesis, University of Nottingham, Nottingham, UK, 1994. 
26. Frost, M.W.; Fleming, P.R.; Rogers, D.F. dynamic triaxial tests on clay subgrades for analytical pavement design. J. Transp. Eng. 2004, 130, 378-386. [CrossRef]

27. Wang, J.H.; Ling, X.Z.; Li, Q.L.; Zhang, F.; Li, Y. Accumulated permanent strain and critical dynamic stress of frozen silty clay under cyclic loading. Cold. Reg. Sci. Technol. 2018, 153, 130-143. [CrossRef]

28. Zhang, X.; Ren, K. Experimental study on dynamic elastic modulus and critical dynamic stress of cinder-improved soil subgrade. J. Highw. Transp. R. Dev. 2018, 12, 25-32. [CrossRef]

29. Monismith, C.L.; Ogawa, N.; Freeme, C.R. Permanent deformation characteristics of subgrade soils due to repeated load. Transp. Res. Rec. 1975, 537, 1-17.

30. Barksdale, R.D. Laboratory evaluation of rutting in base course material. In Proceedings of the 3rd International Conference on Structural Design of Asphalt Pavement, London, UK, 11-15 September 1972; pp. 161-174.

31. Hornych, P.; Piau, J.M. Towards computation tools for the assessment of rutting of flexible pavements. In Proceedings of the 6th International Conference on the Bearing Capacity of Roads, Railways and Airfields, Lisbon, Portugal, 24-26 June 2002; pp. 57-74.

32. Li, D.Q.; Selig, E.T. Cumulative plastic deformation for fine-grained subgrade soils. J. Geotech. Eng. 1996, 122, 1006-1013. [CrossRef]

33. Chai, J.C.; Miura, N. Traffic-load-induced permanent deformation of road on soft subsoil. J. Geotech. Geoenviron. 2002, 128, 907-916. [CrossRef]

34. Wu, T.Y.; Cai, Y.Q.; Guo, Y.; Ling, D.S.; Wang, J. Influence of shear stress level on cyclic deformation behaviour of intact Wenzhou soft clay under traffic loading. Eng. Geol. 2017, 228, 61-70. [CrossRef]

35. Moghaddas-Nejad, F.; Small, J. Resilient and permanent characteristics of reinforced granular materials by repeated load triaxial tests. Geotech. Test. J. 2003, 26, 152-166.

36. Stewart, H.E. Permanent strains from cyclic variable-amplitude loadings. J. Geotech. Eng. 1986, 112, 646-660. [CrossRef]

37. Xu, F.; Zhai, B.; Leng, W.M.; Yang, Q.; Leng, H.K.; Nie, R.S. Probabilistic method for evaluating the permanent strain of unbound granular materials under cyclic traffic loading. Constr. Build. Mater. 2020, 251, 118975. [CrossRef]

38. Lekarp, F.; Dawson, A. Modelling permanent deformation behaviour of unbound granular materials. Constr. Build. Mater. 1998, 12, 9-18. [CrossRef]

39. El-Badawy, S.M.; Witczak, M. Development of a universal permanent strain model for subgrade pavement materials. In Proceedings of the 86th Annual Meeting of the Transportation Research Board, Washington, DC, USA, 21-25 January 2007; p. $07-2318$.

40. Xiao, Y.J.; Tutumluer, E.; Mishra, D. Performance evaluations of unbound aggregate permanent deformation models for various aggregate physical properties. Transp. Res. Rec. 2015, 2525, 20-30. [CrossRef]

41. Romanoschi, S.A. Empirical models for permanent deformation of subgrade soils from the data collected at the pavement subgrade performance study. J. Mater. Civ. Eng. 2017, 29, 04016236. [CrossRef]

42. NRA (TB 10001-2016). Code for Design of Railway Earth Structure; China Railway Publishing House: Beijing, China, 2016.

43. ASTM (ASTM D2487-17e1). Standard Practice for Classification of Soils for Engineering Purposes (Unified Soil Classification System); ASTM: West Conshohocken, PA, USA, 2020.

44. ASTM (ASTM D1557-12). Standard Test Methods for Laboratory Compaction Characteristics of Soil Using Modified Effort; ASTM: West Conshohocken, PA, USA, 2012.

45. ASTM (ASTM D7181-20). Standard Test Method for Consolidated Drained Triaxial Compression Test for Soils; ASTM: West Conshohocken, PA, USA, 2020.

46. Yan, C.B.; Wang, H.J.; Xu, X.; Zhang, Y.C. Identifying fatigue damage of mudded intercalations based on dynamic triaxial test. Eng. Geol. 2021, 280, 105933. [CrossRef]

47. Karg, C.; Haegeman, W. Elasto-plastic long-term behavior of granular soils: Experimental investigation. Soil. Dyn. Earthq. Eng. 2009, 29, 155-172. [CrossRef]

48. Cerni, G.; Cardone, F.; Virgili, A.; Camilli, S. Characterisation of permanent deformation behaviour of unbound granular materials under repeated triaxial loading. Constr. Build. Mater. 2012, 28, 79-87. [CrossRef]

49. Tang, L.; Yan, M.H.; Ling, X.Z.; Tian, S. Dynamic behaviours of railway's base course materials subjected to long-term low-level cyclic loading: Experimental study and empirical model. Géotechnique 2017, 67, 537-545. [CrossRef]

50. Mehdizadeh, A.; Disfani, M.M.; Evans, R.; Arulrajah, A.; Ong, D. Mechanical consequences of suffusion on undrained behaviour of a gap-graded cohesionless soil-An experimental approach. Geotech. Test. J. 2017, 40, 20160145. [CrossRef]

51. Li, Z.C. Study on the Vertical Load Transmission through the Track Structure and the Characteristics of Subgrade Dynamic Stress; China Academy of Railway Science: Beijing, China, 2000; pp. 4-5.

52. Xiao, H.; Liu, G.P.; Yan, D.W.; Zhao, Y.; Wang, J.Q.; Wang, H.Y. Field test and numerical analysis of insulated rail joints in heavy-haul railway. Constr. Build. Mater. 2021, 298, 123905. [CrossRef]

53. Shi, Z.Y.; Wang, K.Y.; Zhang, D.W.; Chen, Z.G.; Zhai, G.H.; Huang, D.X. Experimental investigation on dynamic behaviour of heavy-haul railway track induced by heavy axle load. Transport 2019, 34, 351-362. [CrossRef]

54. Li, P.; Ling, C.X.; Zhang, F.; Li, Y.; Zhao, Y.Y. Field testing and analysis of embankment vibrations induced by heavy haul trains. Shock. Vib. 2017, 7410836, 1-14. [CrossRef]

55. Thevakumar, K.; Indraratna, B.; Ferreira, F.B.; Carter, J.; Rujikiatkamjorn, C. The influence of cyclic loading on the response of soft subgrade soil in relation to heavy haul railways. Transp. Geotech. 2021, 29, 100571. [CrossRef] 
56. Indraratna, B.; Ngo, T.; Ferreira, F.B.; Rujikiatkamjorn, C.; Tucho, A. Large-scale testing facility for heavy haul track. Transp. Geotech. 2021, 28, 100517. [CrossRef]

57. Mei, H.H.; Leng, W.M.; Nie, R.S.; Liu, W.J.; Chen, C.; Wu, X.W. Random distribution characteristics of peak dynamic stress on the subgrade surface of heavy-haul railways considering track irregularities. Soil. Dyn. Earthq. Eng. 2019, 116, 205-214. [CrossRef]

58. Hu, Z.X. Soil Mechanics and Environmental Geotechnology; Tongji University Press: Shanghai, China, 1997.

59. Mehdizadeh, A.; Disfani, M.M.; Evans, R.; Arulrajah, A.; Ong, D. Discussion of 'Development of an Internal Camera-Based Volume Determination System for Triaxial Testing' by S.E. Salazar, A. Barnes and R.A. Coffman. Geotech. Test. J. 2016, 39, 165-168.

60. Liu, S.F.; Yang, Y.J.; Forrest, J. Grey Data Analysis: Methods, Models, and Applications; Springer: Singapore, 2017.

61. Cui, K.; Jing, X. Research on prediction model of geotechnical parameters based on bp neural network. Neural Comput. Appl. 2018, 31, 8205-8215. [CrossRef]

62. Prusty, J.K.; Pradhan, B. Multi-response optimization using Taguchi-Grey relational analysis for composition of fly ash-ground granulated blast furnace slag based geopolymer concrete. Constr. Build. Mater. 2020, 241, 118049. [CrossRef]

63. Rajeswari, B.; Amirthagadeswaran, K.S. Experimental investigation of machinability characteristics and multi-response optimization of end milling in aluminium composites using RSM based grey relational analysis. Measurement 2017, 105, 78-86. [CrossRef]

64. Shi, S.X.; Fei, H.Y.; Xu, X.G. Application of a FMEA method combining interval 2-tuple linguistic variables and grey relational analysis in preoperative medical service process. IFAC-PapersOnLine 2019, 52, 1242-1247. [CrossRef]

65. Javed, S.A.; Mahmoudi, A.; Khan, A.M.; Javed, A.M.; Javed, S.; Liu, S.F. A critical review: Shape optimization of welded plate heat exchangers based on grey correlation theory. Appl. Therm. Eng. 2018, 144, 593-599. [CrossRef]

66. Wu, L.Z.; Li, S.H.; Huang, R.Q.; Xu, Q. A new grey prediction model and its application to predicting landslide displacement. Appl. Soft Comput. J. 2020, 95, 106543. [CrossRef]

67. Liu, D.; Li, M.X.; Ji, Y.; Fu, Q.; Li, M.; Faiz, M.A.; Ali, S.; Li, T.X.; Cui, S.; Khan, M.I. Spatial-temporal characteristics analysis of water resource system resilience in irrigation areas based on a support vector machine model optimized by the modifed gray wolf algorithm. J. Hydrol. 2020, 2020, 125758. [CrossRef]

68. Liu, W.J.; Zhang, J.; Jin, M.Z.; Liu, S.F.; Chang, X.Y.; Xie, N.M.; Wang, Y.T. Key indices of the remanufacturing industry in China using a combined method of grey incidence analysis and grey clustering. J. Clean. Prod. 2017, 168, 1348-1357. [CrossRef]

69. Mathworks. MATLAB Version 8.6.0; The Mathworks Inc.: Natick, MA, USA, 2015.

70. Wang, L.; Bi, X.H. Risk assessment of knowledge fusion in an innovation ecosystem based on a GA-BP neural network. Cogn. Syst. Res. 2021, 66, 201-210. [CrossRef]

71. Jiang, C.; Wen, J.W.; Li, M.Z.; You, T.P. Calculation on enantiomeric excess of catalytic asymmetric reactions of diethylzinc addition to aldehydes with topological indices and artificial neural network. J. Mol. Catal. 2006, 258, 191-197.

72. Costanza, G.; Tata, M.E.; Ucciardello, N. Superplasticity in PbSn60: Experimental and neural network implementation. Comp. Mater. Sci. 2006, 37, 226-233. [CrossRef]

73. Xu, L.J.; Xing, J.D.; Wei, S.Z.; Zhang, Y.Z.; Long, R. Artificial neural network prediction of retained austenite content and impact toughness of high-vanadium high-speed steel (HVHSS). Mater. Sci. Eng. 2006, 433, 251-256. [CrossRef]

74. Chakraverty, S.; Sigh, V.P.; Sharma, R.K. Regression based weight generation algorithm in neural network for estimation of frequencies of vibrating plates. Comput. Methods Appl. Mech. Eng. 2006, 195, 4194-4202. [CrossRef]

75. Rumelhart, D.W.; Hinton, G.E.; Williams, R.J. Learning representations by back-propagating errors. Nature 1989, 323, 533-536. [CrossRef]

76. Chen, M. Principle and Example of MATLAB Neural Network; Tsinghua University Press: Beijing, China, 2013.

77. Dawson, A.; Mundy, M.; Huhtala, M. European research into granular material for pavement bases and subbases. Transp. Res. Rec. 2000, 1721, 91-99. [CrossRef]

78. Wang, K.Y.; Zhuang, Y.; Geng, X.Y. Experimental research on critical dynamic Stress of coarse-grained soil in railway subgrade. Rock. Soil Mech. 2020, 41, 1865-1873.

79. Xu, F.; Yang, Q.; Liu, W.J.; Leng, W.M.; Nie, R.S.; Mei, H.H. Dynamic stress of subgrade bed layers subjected to train vehicles with large axle loads. Shock. Vib. 2018, 2018, 2916096. [CrossRef]

80. Shan, Y.; Albers, B.; Savidis, S.A. Influence of different transition zones on the dynamic response of track-subgrade systems. Comput. Geotech. 2013, 48, 21-28. [CrossRef] 